\title{
Transposition
}

Musique et Sciences Sociales

$7 \mid 2018$

Le prix de la musique

\section{Le subventionnement des concerts symphoniques dans les départements français entre 1861 et 1969}

Une préhistoire de la politique musicale de l'État et une géographie de la France musicale

\section{Yannick Simon}

\section{OpenEdition}

\section{Journals}

Édition électronique

URL : http://journals.openedition.org/transposition/1821

DOI : $10.4000 /$ transposition. 1821

ISSN : 2110-6134

Éditeur

CRAL - Centre de recherche sur les arts et le langage

\section{Référence électronique}

Yannick Simon, «Le subventionnement des concerts symphoniques dans les départements français entre 1861 et 1969 », Transposition [En ligne], 7 | 2018, mis en ligne le 15 septembre 2018, consulté le 15 novembre 2019. URL : http://journals.openedition.org/transposition/1821 ; DOI : 10.4000/ transposition. 1821

Ce document a été généré automatiquement le 15 novembre 2019.

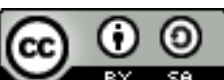

La revue Transposition est mise à disposition selon les termes de la Licence Creative Commons Attribution - Partage dans les Mêmes Conditions 4.0 International. 


\section{Le subventionnement des concerts symphoniques dans les départements français entre 1861 et 1969}

Une préhistoire de la politique musicale de l'État et une géographie de la France musicale

\section{Yannick Simon}

1 Le défaut de politique musicale de l'État avant la fondation d'un secrétariat d'État aux Affaires culturelles en 1959 ne signifie pas l'absence de diffusion de la musique sur l'ensemble du territoire français. Si, pour plagier André Malraux, le ministre des Affaires culturelles nommé par le général de Gaulle à ce poste créé spécialement pour lui en 1959, on peut dire que l'État ne l'a pas attendu pour ne rien faire ${ }^{1}$, les collectivités locales, et plus encore les forces vives et les «mélomanes actifs ${ }^{2}$ » des territoires ont fait preuve d'un prosélytisme ayant obligé les pouvoirs publics à réagir dès 1878. C'est ce que les travaux de Myriam Chimènes sur le budget de la musique ont montré ${ }^{3}$. La présente étude s'inscrit dans leur prolongement, en tentant de décrypter ce que dissimule la ligne « concerts populaires » du budget de la France, et dans la perspective de dresser une géographie musicale de la France aux $\mathrm{XIX}^{\mathrm{e}}$ et $\mathrm{XX}^{\mathrm{e}}$ siècles.

2 Il est pourtant indéniable que, jusqu'au «Plan de dix ans pour l'organisation des structures musicales françaises » initié par Marcel Landowski en 1969, l'État, plutôt qu'il ne finance l'activité symphonique des départements, apporte d'abord sa caution à des sociétés de concerts ${ }^{4}$. Plus que des moyens financiers indispensables, il délivre des encouragements, c'est-à-dire une protection prenant la forme d'une subvention. Pour autant, tout en opérant une rupture radicale, au niveau des moyens mis en œuvre et des objectifs poursuivis, le Plan Landowski s'inscrit dans la continuité d'une structuration progressive de la politique musicale de l'État. Celle-ci prend la forme d'une commission dont les attributions toujours plus larges en font progressivement une sorte de Conseil supérieur de la musique au sein de l'administration des Beaux- 
arts $^{5}$. Cette structuration s'accompagne, à partir des années 1930, d'une ambition corporative et nationaliste - dont la période de Vichy n'est pas le paroxysme - qui prédomine sur le renouvellement des publics. Malgré une incontestable prise en considération de l'activité musicale dans les départements depuis le début de la $\mathrm{III}^{\mathrm{e}}$ République, le rapport entre les institutions musicales, de facto parisiennes, et les sociétés des régions n'est pas fondamentalement modifié avant le Plan Landowski. Celui-ci stabilise une géographie musicale de la France jusqu'à présent mouvante, mais néanmoins marquée par des points d'ancrage importants et inégalement répartis sur le territoire.

3 Tout en étant quantitative, cette étude est à la recherche de ce que nous disent les chiffres de la création musicale, du goût musical et de la diffusion de la musique en France dans le domaine spécifique du concert symphonique sur une longue période. Elle débute avec la naissance des Concerts populaires de musique classique en 1861, sous la conduite du chef d'orchestre Jules Pasdeloup'. La conception, l'organisation, la programmation, le public visé, le rayonnement et le succès des Concerts Pasdeloup en font un élément fondamental de l'histoire du concert symphonique en France. Il marque le début d'une longue période qui se clôt en 1969 avec l'adoption du Plan Landowski.

\section{L'absence de politique et de décentralisation culturelles}

4 En France, il faut attendre l'avènement de la $V^{\mathrm{e}}$ République et la création d'un secrétariat d'État aux Affaires culturelles pour voir se dessiner et se mettre en place une véritable politique culturelle, qui plus est, à l'échelle du territoire français ${ }^{7}$. La période précédente s'était étendue sur près d'un siècle et caractérisée par une incertitude née de l'abandon brutal de la fonction principale de la culture jusqu'en 1870, l'apparat et le rayonnement du pouvoir monarchique ou impérial. Ce renoncement imprévu ne se traduit pas par l'émergence immédiate d'un nouveau paradigme. Globalement, entre 1861 et 1969 , la politique culturelle reste un ensemble composite, flou et toujours en cours de redéfinition par des acteurs différents qui se contestent la légitimité de l'entreprendre. En effet, longtemps, les artistes et les intellectuels ont eu les premiers le monopole de cette définition et se sont déclarés en faveur de "la séparation des Beaux-arts et de l'État ${ }^{8}$. " Cette défiance a pour corollaire l'absence d'engagement financier de l'État dans le domaine de la culture. Seules les institutions nationales sises à Paris bénéficient de son aide. Mais cette forme de séparation des pouvoirs revendiquée par les artistes eux-mêmes évolue progressivement. Ils finissent par s'approprier le discours sur l'État protecteur et son pendant, le financement public. Dans le même temps, comme le montrent les rapports qui accompagnent chaque année le vote du budget de l'État, les parlementaires s'immiscent dans le débat sur la définition de la politique culturelle: utilité économique, grandeur nationale et moralisation des masses sont les trois arguments mis en avant par l'État pour justifier son intervention dans le domaine culturel. Dans cette optique, une meilleure répartition des moyens dans l'espace français n'est jamais perçue comme une priorité.

5 Pendant un siècle, la décentralisation est le parent pauvre d'une politique culturelle de l'État très embryonnaire. Car si le centre se fait un devoir d'irriguer sa périphérie, il ne 
s'en donne jamais les moyens. Et même si, comme nous le verrons, progressivement à partir de 1878, des crédits sont alloués à cette cause, ils le sont dans des proportions très faibles. Dans ce domaine, plus que les réalisations, ce sont les écrits et des vœux pieux qui prévalent sur l'ensemble de la période étudiée. Pour le moins, ils témoignent de la prise de conscience progressive du problème. Sous le Second Empire, la question est d'autant plus d'actualité que se développe à grande vitesse le réseau ferroviaire, instrument idéal de la décentralisation et de la circulation de la musique.

6 Paru en 1857 dans la Revue des deux mondes, un article du musicographe Paul Scudo intitulé «La musique en province » est l'un des signes de la prise de conscience, dans la capitale, de la renaissance de l'activité musicale dans les départements français'. Scudo fait remonter à une vingtaine d'années la résurrection d'une vie musicale annihilée par la Révolution ${ }^{10}$. Tout en constatant le "triste état ${ }^{11}$ » des théâtres lyriques, il loue l'activité des sociétés musicales qui ont « beaucoup contribué à la propagation de l'art musical ${ }^{12}$.» Mais tout en présentant la centralisation comme un reste de la monarchie, Scudo n'associe pas son constat à une requête en faveur de ces nouveaux acteurs de la vie musicale contrairement à Antoine-Louis Malliot.

7 Compositeur et chanteur né à Lyon et exerçant son activité de critique musical à Rouen à partir de 1846, Malliot ${ }^{13}$ est un militant de la décentralisation lyrique à laquelle il consacre un long plaidoyer dans un ouvrage paru en 1863, La musique au théatre ${ }^{14}$. En 1865, dans le prolongement du décret du 6 janvier 1864 relatif à la liberté de construire et d'exploiter un théâtre qui répond partiellement à ses attentes ${ }^{15}$, Malliot adresse une pétition au Sénat en faveur de la « Fondation des théâtres impériaux de province ${ }^{16}$. » Il réclame que la ville de Paris fournisse elle-même à ses propres théâtres la moitié de ce que l'État leur donne (1600 000 francs) et que les 800000 francs ainsi économisés soient répartis entre les établissements des régions, dénommés "théâtres impériaux de la province ", en contribuant à leur financement à hauteur de $50 \%$ de la subvention municipale; cette aide serait soumise à la condition que les villes susceptibles d'en bénéficier créent un conservatoire de musique. Tout comme la suivante présentée en $1866^{17}$, cette requête ne connaît pas une issue positive. Elle n'en traduit pas moins une attente, celle des acteurs de la vie musicale des départements, et un besoin, celui des compositeurs dont le nombre croissant les incite à rechercher de nouveaux débouchés pour leurs ouvrages lyriques en dehors de la capitale ${ }^{18}$. La décentralisation musicale de papier ne s'arrête pourtant pas avec l'échec des deux pétitions de Malliot $^{19}$. Les rapports et les projets avortés ne manquent pas mais ils sont moins concrets que certaines initiatives personnelles isolées.

8 Les quarante-quatre concerts de l'orchestre des Concerts populaires de musique classique et de son chef d'orchestre Jules Pasdeloup en dehors de Paris entre 1864 et 1883 sont au nombre de celles-là̀ ${ }^{20}$. Il n'est pas à exclure que ces voyages d'une formation comptant parfois jusqu'à soixante-quatorze instrumentistes soient une première en France. Certes, des solistes se déplacent depuis longtemps sur l'ensemble du territoire ${ }^{21}$, mais il est probable que les voyages de l'orchestre de Pasdeloup sont une innovation. Ils doivent beaucoup au réseau ferroviaire seul en mesure de permettre le déplacement d'une telle cohorte et le transport des instruments. Pasdeloup et son orchestre effectuent des déplacements uniques pour un ou deux concerts et, dans un cas (à Bordeaux en 1882), pour une série de treize représentations. Ils entreprennent aussi quatre tournées qui les amènent à visiter à chacune d'entre elles de deux à cinq villes. Opération à la fois éducative et commerciale, les concerts Pasdeloup 
décentralisés ne bénéficient d'aucune aide de l'État. Leur rentabilité fait d'autant moins de doute que la pratique des voyages orchestraux se poursuit bien après le décès de Pasdeloup en 1887. Édouard Colonne et Charles Lamoureux l'imitent avec leur propre formation. Bien accueillies par le public, ces initiatives le sont beaucoup moins par les acteurs de la vie musicale locale qui y voient une forme de concurrence déloyale ${ }^{22}$. Leurs protestations s'appuient sur un fait: la vie musicale dans les villes françaises n'est pas atone. C'est cette réalité que nous allons dorénavant tenter d'aborder non sans mesurer la difficulté d'une telle entreprise.

Restée au stade d'incantation, la décentralisation considérée comme une politique volontariste induite par le centre n'est pas pertinente pour comprendre la réalité de la vie musicale dans les départements français avant les années 1970. Parallèlement, il convient d'admettre que l'absence d'implication de l'État n'est nullement la conséquence d'un manque. En réalité, en marge, en complément ou en remplacement de l'activité théâtrale, des villes françaises, grandes, moyennes ou plus petites abritent une vie musicale plus ou moins intense. Cette activité est autonome, dans la mesure où elle repose sur les efforts d'individus et/ou de groupes sociaux, mais aussi parce qu'elle s'autofinance, avec le concours plus ou important des collectivités locales prioritairement les municipalités et, dans une moindre mesure, les conseils généraux ${ }^{23}$. Dans le même temps, cette activité est en partie dépendante du centre, pour ce qui est des instrumentistes et chanteurs, de leur formation, ou encore des partitions qu'ils interprètent.

Cette histoire de la vie musicale en France dans les départements depuis la Révolution reste à écrire. La bibliographie consacrée au Concert en France des origines à 1914 pourrait donner à penser que l'espace musical français a fait l'objet de nombreuses publication $\mathrm{s}^{24}$. Néanmoins, indépendamment des monographies dédiées à une ville, ou plus rarement à une région, le sujet n'a pas donné lieu à une synthèse même sur une période limitée, que ce soit pour le théâtre lyrique ou pour la musique instrumentale. En revanche, le cadre scientifique de la recherche est clairement identifié grâce aux ouvrages publiés entre 2003 et 2008 dans le prolongement du projet « Musical Life in Europe (1600-1900): Circulation, Institutions, Representation» (European Science Foundation), qui en sont naturellement les fondements ${ }^{25}$.

\section{Les débuts du financement de la musique par l'État (1878-1914)}

\section{L'action de Pasdeloup}

Si elle ne saurait suffire à évaluer ses ambitions et réalisations, l'approche quantitative offre un coup d'œil éclairant sur la politique culturelle de l'État. Quelles sommes et quelle part de son budget l'État consacre-t-il à la musique ? Telle était la question posée par Myriam Chimènes pour la période de la $\mathrm{III}^{\mathrm{e}}$ République $^{26}$. La réponse tient en quelques mots : très peu et encore moins pour les départements! Alors qu'il entretient les institutions lyriques de la capitale depuis le xvII siècle, l'État n'accorde aucune subvention directe et pérenne à une société de concerts avant $1878^{27}$. Cette année-là, Jules Pasdeloup adresse une pétition aux députés dans laquelle il réclame l'aide de la puissance publique pour financer ses concerts populaires de musique classique ${ }^{28}$. Il obtient gain de cause et le budget de l'État s'enrichit d'un nouveau chapitre intitulé 
«Encouragements aux concerts populaires" (chapitre $\mathrm{n}^{\circ} 44$ bis) qui profite simultanément à l'Association artistique des concerts du Châtelet d'Édouard Colonne. Très faibles (20000 francs pour Pasdeloup, 3500 francs pour Colonne et 1500 francs répartis entre plusieurs sociétés partiellement identifiées), les sommes en jeu sont dix fois inférieures à celles consacrées à l'enseignement musical et près de cinquante fois à celles réservées à l'art lyrique. Il n'empêche que le financement de la musique symphonique est la principale innovation de la $\mathrm{III}^{\mathrm{e}}$ République dans ce domaine artistique avant la politique des commandes d'œuvres qui n'apparaîtra qu'en $1938^{29}$. Sous des appellations variables, le chapitre budgétaire accordant des subsides aux sociétés de concerts populaires est reconduit d'année en année pendant toute la III ${ }^{\mathrm{e}}$ République. Les principales sociétés parisiennes qui en bénéficient voient leur nom mentionné dans le budget de l'État sous la forme d'un article du chapitre nouvellement créé. C'est le cas pendant presque toute la période étudiée des Concerts Colonne, à partir de 1878, et des Concerts Lamoureux, à partir de $1881^{30}$. Sans en avoir le titre, on peut dire que ces deux sociétés accèdent ainsi au rang d'institutions même si l'État ne finance que très partiellement leurs activités. Les subventions aux autres sociétés, à Paris et dans les départements, font l'objet d'une demande globale apparaissant sur une ou plusieurs lignes budgétaires. Pendant plusieurs décennies, la répartition est ensuite laissée à la discrétion du ministre de l'Instruction publique et des Beaux-arts. Pour les musicologues et les historiens, la distinction entre des subventions pérennes à des sociétés identifiées et le vote d'un budget groupé n'est pas sans conséquence dans la mesure où elle rend plus difficile, partielle ou impossible le recensement des sociétés concernées. Les conséquences de cette visibilité erratique ne sont pas minces puisque le financement par l'État est le seul instrument d'évaluation commun à toutes les sociétés musicales sur l'ensemble du territoire français à partir de 1878. En effet, la pétition adressée à l'État par Pasdeloup cette année-là ne profite pas uniquement à son rédacteur et à son principal concurrent sur le "marché » des concerts symphoniques dominicaux à Paris.

\section{La création d'une ligne budgétaire}

12 L'Association artistique d'Angers est l'une des premières sociétés de concerts départementales à bénéficier d'une aide de l'État ${ }^{31}$. En 1878, elle fait partie des sociétés qui se partagent les 1500 francs inscrits dans le chapitre 44 bis aux côtés des 20000 francs attribués à Pasdeloup et des 3500 francs concédés à Colonne. Il n'est malheureusement pas permis d'identifier les autres sociétés sachant que la société angevine ne reçoit qu'un cinquième de la somme, soit 300 francs. L'année suivante, en 1879, l'aide de l'État à la société angevine est portée à 4000 francs grâce à des crédits restés sans affectation depuis la liquidation du Théâtre-Lyrique et laissés à la disposition du ministre des Beaux-arts, au lieu d'être annulée ${ }^{32}$. Enfin, à l'occasion de la préparation du budget 1881, l'aide est transformée en véritable subvention grâce à la création d'un article du budget intitulé "Concerts populaires, matinées littéraires, sociétés musicales ${ }^{33}$ » au sein du chapitre créé pour Pasdeloup en 1878. Il est doté de 25000 francs répartis entre des sociétés domiciliées à Angers, Bordeaux, Lille et Marseille $^{34}$. Sans pouvoir l'affirmer, on peut supposer que ce sont les mêmes qui avaient obtenu quelques subsides en 1878.

La proposition du gouvernement ne fait pourtant pas consensus ${ }^{35}$. La commission du budget de l'assemblée nationale considère que l'État n'a pas à subventionner les 
concerts des régions, d'une part, parce qu'il prendrait le risque d'être submergé par les demandes, et, d'autre part, parce que la vocation de ces sociétés est purement municipale. Seules les sociétés parisiennes auraient un rayonnement national justifiant l'engagement de l'État:

Il a paru à votre commission que ces subventions devaient être données par les municipalités et non par l'État. C'est à elles qu'il appartient d'encourager des manifestations artistiques qui ont une très heureuse influence dans la ville où elles se produisent, mais dont le reste du pays ne profite pas.

C'est en vain qu'on essaierait d'assimiler les subventions demandées à celles que reçoivent les théâtres ou même les concerts de Paris. Ceux-ci ne sont pas exclusivement Parisiens [sic]. Ils rayonnent, pour ainsi dire, sur tout le pays. Ce sont les œuvres qu'ils représentent, et que seuls ils peuvent représenter, qui alimentent toutes les scènes de province, et par là ils justifient la subvention qu'ils reçoivent de l'État.

Votre commission vous demande de ne pas accepter le crédit qui vous est demandé par le Gouvernement ${ }^{36}$.

Contre l'avis de la commission, la proposition du gouvernement est adoptée par les députés et reprise dans les mêmes termes au Sénat.

Parallèlement à la création de l'article, le chapitre du budget est rebaptisé «Concerts populaires et sociétés musicales des départements ». Il est désormais entièrement consacré aux sociétés de concerts, que leurs activités se déploient à Paris ou dans les départements. Le premier des trois articles est dédié aux Concerts Pasdeloup, le deuxième aux Concerts Colonne - un troisième sera créé l'année suivante pour la Société des nouveaux concerts fondée en 1881 par Charles Lamoureux - et le dernier aux "concerts populaires et sociétés musicales des départements". Strictement identiques, la dénomination du chapitre et celle du nouvel article créé en 1881 ne sont pas sans ambiguïté. N'étant pas spécifiquement dévolu aux seules sociétés de concerts des départements, l'article va rapidement devenir un fourre-tout permettant de réunir des sociétés, d'une part, de tous types y compris des fanfares et des harmonies municipales, et, d'autre part, en tout lieu du territoire français en incluant la capitale.

\section{Un financement brouillon}

L'étude de la dimension budgétaire de l'embryon de politique musicale de l'État est un exercice périlleux qui n'en reste pas moins déterminant dans la perspective de dessiner une géographie de la France musicale. Comme nous avons pu l'observer en 1881, alors que chacune des sociétés de concerts parisiennes institutionnalisées est associée à un article du budget, les sociétés des régions sont traitées globalement dans un article unique. Et si les parlementaires en votent le volume, la répartition reste du ressort de la seule administration des Beaux-arts. Cette pratique artisanale perdure longtemps, ne facilitant pas le travail du chercheur contraint à l'exploration du fonds F/21 des Archives nationales de France et du Journal officiel pour trouver des informations qui sont rarement exhaustives et définitives ${ }^{37}$. C'est en 1909 qu'apparaît pour la première fois une liste complète des sociétés subventionnées dans un document parlementaire. À ces difficultés, viennent s'ajouter d'autres facteurs.

17 L'intitulé des chapitres et articles du budget, la définition des termes qu'ils contiennent et ce qu'ils regroupent sont placés sous le sceau d'une instabilité permanente. Le chapitre créé en 1878 à la demande de Pasdeloup et intitulé «Encouragements aux Concerts populaires » connaît quatre autres titres avant la Première Guerre mondiale : 
"Subventions aux Concerts populaires et aux matinées littéraires»(1879-1880); «Concerts populaires, matinées littéraires, sociétés musicales » (1881-1896); «Concerts populaires et sociétés musicales à Paris et dans les départements »(1897-1900); «Concerts populaires et sociétés musicales à Paris et dans les départements et œuvres de décentralisation artistique» (1901-1914). En outre, cette évolution ne reflète qu'imparfaitement celle du contenu du chapitre, exception faite de la permanence des deux articles consacrés aux Concerts Colonne et Lamoureux pendant toute la période étudiée $^{38}$. De fait, le nombre des articles et leurs titres connaissent de nombreux changements tandis que les bénéficiaires des aides de l'État ne sont pas tous des orchestres symphoniques donnant des concerts populaires. On y trouve aussi des théâtres populaires et des sociétés musicales non symphoniques (fanfares ou harmonies municipales, sociétés de musique de chambre, chœurs) tant parisiennes que régionales. C'est uniquement en 1909 que les sociétés symphoniques et les fanfares ou harmonies municipales sont clairement séparées dans deux chapitres distincts. Par ailleurs, il n'est pas rare que deux sociétés aux activités identiques ne soient pas réunies sous le même article: des sociétés de concerts symphoniques figurent dans l'article consacré aux concerts populaires mais aussi dans celui intitulé « décentralisation artistique » qui voit le jour en 1902. À l'évidence, au regard de son expression budgétaire, l'embryon de politique musicale de l'État se caractérise par une grande confusion qui témoigne de l'absence d'une véritable politique musicale à l'échelle du territoire français clairement définie. Dans ce domaine, le volontarisme s'avère insuffisant. Indépendamment des institutions parisiennes, les régions ne font pas l'objet d'une politique spécifique d'encouragement, bien au contraire. Alors qu'ils étaient réservés à des sociétés provinciales en 1881, les crédits de l'article intitulé "Concerts populaires à Paris et dans les départements " sont affectés à des sociétés parisiennes à hauteur de $50 \%$ en $1907^{39}$. Le rééquilibrage envisagé dans les années suivantes se heurte à la faiblesse des moyens et pose la question de leur dispersion au détriment d'une approche qualitative ${ }^{40}$.

La confusion régnant dans les documents budgétaires rend illusoire toute comparaison qui ne reposerait pas sur une identification précise des sociétés encouragées. Pour autant, il n'est pas inutile d'en revenir aux chiffres globaux mentionnés par Myriam Chimènes ${ }^{41}$. En retranchant de l'ensemble les sommes attribuées aux trois sociétés de concerts parisiennes institutionnalisées (Pasdeloup, Colonne et Lamoureux), on constate que l'État consacre aux concerts des crédits compris entre 25000 francs en 1881 et 135500 francs en 1914. Une augmentation significative mais un volume dérisoire au regard des budgets des sociétés de concerts.

\section{Encouragements et caution de l'État}

19 Il convient de le redire : ne reposant pas sur des sources exhaustives, le recensement des subventions distribuées par l'État aux sociétés de concerts non institutionnelles comporte une part d'approximation que nous avons naturellement tenté de réduire, par le dépouillement des documents d'archives et la consultation du Journal officiel. Pour la période postérieure à 1903 , on pourra utiliser en priorité le «Relevé des allocations aux sociétés musicales, concerts populaires et œuvre de décentralisation artistique » répertoriant département par département les subventions versées par l'État à des sociétés musicales entre 1904 et $1925^{42}$. Nous le ferons néanmoins avec prudence dans la mesure où, d'une part, il n'a pas été complété pendant toute la 
période de la Première Guerre mondiale, et, d'autre part, parce que la distinction n'est pas opérée entre les différentes formes de sociétés ${ }^{43}$. Il n'empêche que la tenue de ce répertoire est le signe d'une évolution significative du financement de l'État. En 1902, était apparu un nouvel article du budget intitulé «Décentralisation artistique ». Doté de 25000 francs, il venait s'ajouter à celui consacré aux concerts populaires qui restait alimenté, pour sa part, à hauteur de 28000 francs.

La période antérieure à la création de cet article budgétaire se caractérise par un financement réduit tant par le volume que par le nombre des villes concernées. Elles sont au nombre de dix entre 1881 et 1902 :

- Angers : Société des concerts populaires

- Bordeaux : Société de Sainte-Cécile

- Boulogne-sur-Mer : Société des concerts du conservatoire

- Lille : Société des concerts populaires

- Lyon [Sociétés indéterminées]

- Marseille : Société des concerts populaires et Association artistique des concerts classiques

- Nancy : Concerts populaires / Concerts du conservatoire

- Perpignan : Société de musique classique

- Roubaix : Association symphonique des concerts du conservatoire

- Valenciennes : Société des concerts populaires

21 Dans cet ensemble, on relèvera en priorité le nom des sociétés ayant bénéficié d'une subvention de l'État dès 1881 : la Société des concerts populaires d'Angers (fondée en 1877), la Société de Sainte-Cécile de Bordeaux (1843), la Société des concerts populaires de Lille (1877), la Société des concerts populaires de Marseille (1880). Cette dernière est la seule à connaître une existence éphémère puisqu'elle disparaît en 1884 et cède sa place à la plus pérenne Association artistique des concerts classiques à partir de 1886 . On gardera en mémoire le nom de ces villes dont l'activité symphonique est pratiquement constante et intense pendant toute la période étudiée. À l'exception de Marseille, elles seront toutes bénéficiaires du Plan Landowski après 1969. Sans être également réparties, elles forment ensemble l'esquisse d'un grand arc aux pourtours du territoire français dont la capitale est l'épicentre. 


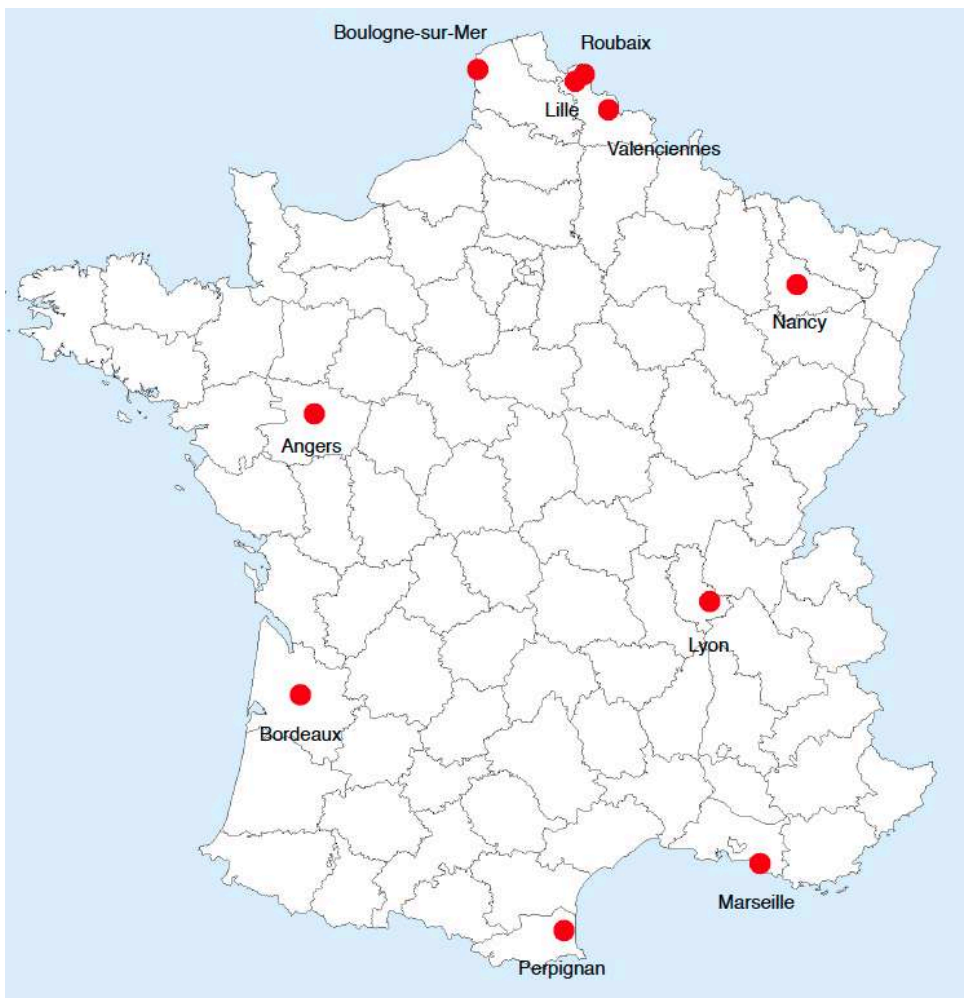

Sociétés de concerts subventionnées entre 1881 et 1902

Il est malheureusement impossible de déterminer précisément sur l'ensemble de la période 1881-1902 le montant des subventions reçues par chacune de ces quatre sociétés. Les chiffres sont néanmoins connus avec assurance pour l'une d'entre elle, l'Association artistique d'Angers. Entre 1881 et 1893, date à laquelle la société interrompt ses activités (avant de les reprendre en 1898), elle perçoit de l'État entre 5000 francs et 8000 francs $^{44}$. Malgré l'absence d'éléments de comparaison, tout porte à croire que l'Association artistique d'Angers est la société de concerts française la mieux dotée par l'État. Bien que connus uniquement à partir de 1896, les chiffres pour les autres sociétés le confirment. On peut estimer qu'ils sont inchangés depuis plusieurs années, voire même depuis 1881, ou, s'ils ont évolué, qu'ils ont plutôt augmenté. De 1896 à 1902, la Société de Sainte-Cécile de Bordeaux perçoit entre 2400 francs et 2500 francs, la Société des concerts populaires de Lille entre 2000 francs et 200 francs et l'Association artistique des concerts classiques de Marseille entre 5000 francs et 5500 francs.

Les autres villes sont subventionnées plus tardivement et dans des proportions plus faibles. La première concernée est Perpignan pour sa Société de musique classique fondée en 1880. Pour le moins, elle reçoit une subvention de 500 francs en 1884 et 1885, puis, entre 1886 et 1891, un subside d'un montant indéterminé. Fondés en 1884, les Concerts populaires de Nancy se voient attribuer une subvention de 1000 francs à partir de 1886. Il n'est pour autant pas permis d'affirmer qu'elle est reconduite tous les ans et, si elle l'est, à la même hauteur ${ }^{45}$. Deux villes du département du Nord situées à proximité de Lille, Valenciennes et Roubaix, s'ajoutent à cet ensemble. La première pour la Société des concerts populaires fondée en 1888. Elle perçoit entre 300 francs et 500 francs à partir de 1893. La seconde pour l'Association symphonique de l'école nationale de musique fondée en 1889. De 1895 à 1914, elle reçoit 500 francs par an. Non 
loin de là, à Boulogne-sur-Mer, la Société des concerts du conservatoire se voit attribuer une gratification en 1891. Dernier maillon du cercle qui entoure la capitale, la ville de Lyon est mentionnée à quelques reprises entre 1878 et 1902 dans des documents budgétaires sans qu'il soit permis de déterminer avec précision le nom des sociétés concernées - la principale de cette ville, la Société des grands concerts, ne voit le jour qu'en 1905.

Le financement des concerts s'accroit et s'élargit grâce à l'introduction de l'expression puis de l'article « Décentralisation artistique » dans le chapitre du budget consacré aux concerts en $1901^{46}$. Même si les effets ne se font sentir qu'en 1903, cet article est doté d'un montant de 25000 francs en 1902, soit une somme presque identique à celle réservée aux concerts populaires et aux sociétés musicales. Avant d'être celui d'une ambition, l'introduction de cet article est le signe d'un échec puisque, contrairement à celui consacré aux concerts, qui aurait dû être réservé aux régions, il exclut tout financement de la vie musicale à Paris. Alors qu'elles étaient moins de huit chaque année jusqu'en 1902, les sociétés de concerts symphoniques subventionnées sont au nombre de dix-neuf en 1911 même si une incertitude persiste du fait de la confusion entre les sociétés de concerts symphoniques et les sociétés musicales. Outre celles déjà présentes avant 1903, figurent désormais des sociétés ayant pour siège douze autres villes $^{47}$ :

\begin{tabular}{|c|c|c|c|c|}
\hline Ville & Nom de la société & $\begin{array}{l}\text { Date de la } \\
\text { fondation }\end{array}$ & $\begin{array}{l}\text { Dates extrêmes du } \\
\text { subventionnement sur } \\
\text { la période étudiée }\end{array}$ & $\begin{array}{l}\text { Montant minimal } \\
\text { et maximal de la } \\
\text { subvention (en } \\
\text { francs) }\end{array}$ \\
\hline Amiens* & $\begin{array}{l}\text { Société des auditions } \\
\text { classiques }\end{array}$ & & 1904-1914 & $50 / 150$ \\
\hline Angers & $\begin{array}{l}\text { Société des concerts } \\
\text { populaires }\end{array}$ & 1877 & $1881-1914$ & $3000 / 8000$ \\
\hline Angoulême* & $\begin{array}{l}\text { Société des concerts } \\
\text { populaires }\end{array}$ & & $1904-1914$ & $300 / 300$ \\
\hline Belfort* & $\begin{array}{l}\text { Société } \\
\text { philharmonique }\end{array}$ & & $1907-1913$ & $50 / 300$ \\
\hline Besançon* & $\begin{array}{l}\text { Société des concerts } \\
\text { symphoniques }\end{array}$ & 1907 & 1908-1914 & $25 / 300$ \\
\hline Bordeaux & $\begin{array}{l}\text { Société de Sainte- } \\
\text { Cécile }\end{array}$ & 1843 & 1881-1914 & $2400 / 3500$ \\
\hline $\begin{array}{l}\text { Boulogne- } \\
\text { sur-Mer }\end{array}$ & $\begin{array}{l}\text { Société des concerts } \\
\text { du conservatoire }\end{array}$ & & 1891 & ? \\
\hline Caen* & $\begin{array}{l}\text { Association } \\
\text { artistique } \\
\text { grands des } \\
\text { caennais }\end{array}$ & & $1908-1911$ & $150 / 800$ \\
\hline
\end{tabular}




\begin{tabular}{|c|c|c|c|c|}
\hline La Rochelle* & $\begin{array}{l}\text { Société } \\
\text { symphonique des } \\
\text { concerts } \\
\text { populaires }^{48}\end{array}$ & & $1910-1913$ & $100 / 100$ \\
\hline \multirow[b]{2}{*}{ Le Havre* } & Société Sainte-Cécile & 1858 & $1904-1913$ & $300 / 300$ \\
\hline & $\begin{array}{l}\text { Association } \\
\text { artistique des } \\
\text { concerts populaires }\end{array}$ & 1891 & 1913 & 500 \\
\hline Lille & $\begin{array}{l}\text { Société des concerts } \\
\text { populaires }\end{array}$ & 1877 & 1881-1914 & $2000 / 4000$ \\
\hline \multirow{2}{*}{ Lyon } & $\begin{array}{l}\text { Sociétés } \\
\text { indéterminées }\end{array}$ & & $?$ & $?$ \\
\hline & $\begin{array}{l}\text { Société des grands } \\
\text { concerts }\end{array}$ & 1905 & $1908-1914$ & $300 / 2500$ \\
\hline \multirow{2}{*}{ Marseille } & $\begin{array}{l}\text { Société des concerts } \\
\text { populaires }\end{array}$ & & 1881 & $?$ \\
\hline & $\begin{array}{l}\text { Association } \\
\text { artistique des } \\
\text { concerts classiques }\end{array}$ & 1886 & $1891-1914$ & $5000 / 5500$ \\
\hline Montpellier* & Schola cantorum & & 1906-1909 & $500 / 500$ \\
\hline Nancy & $\begin{array}{l}\text { Concerts populaires } \\
/ \quad \text { Concerts du } \\
\text { conservatoire }\end{array}$ & 1884 & $1886-1914$ & $350 / 1000$ \\
\hline Nantes* & $\begin{array}{l}\text { Association nantaise } \\
\text { des grands concerts }\end{array}$ & 1911 & $1911-1913$ & $1500 / 1500$ \\
\hline Narbonne* & $\begin{array}{l}\text { Société des concerts } \\
\text { populaires }\end{array}$ & & 1904-1914 & $100 / 300$ \\
\hline Perpignan & $\begin{array}{l}\text { Société de musique } \\
\text { classique }\end{array}$ & 1880 & $1884-1902$ & $? / 500$ \\
\hline Rennes* & Société des concerts & 1874 & $1909-1914$ & $500 / 1000$ \\
\hline Roubaix & $\begin{array}{l}\text { Association } \\
\text { symphonique de } \\
\text { l'école nationale de } \\
\text { musique }\end{array}$ & 1889 & $1895-1914$ & $500 / 500$ \\
\hline Toulouse* & $\begin{array}{l}\text { Société des concerts } \\
\text { du conservatoire }\end{array}$ & 1902 & $1903-1914$ & $1200 / 2500$ \\
\hline
\end{tabular}




\begin{tabular}{|l|l|l|l|l|}
\hline \multirow{2}{*}{ Valenciennes } & $\begin{array}{l}\text { Société des concerts } \\
\text { populaires }\end{array}$ & 1888 & $1891-1901$ & $300 / 300$ \\
\cline { 2 - 6 } & $\begin{array}{l}\text { Société des concerts } \\
\text { du conservatoire }\end{array}$ & 1913 & $1913-1914$ & $200 / 200$ \\
\hline
\end{tabular}

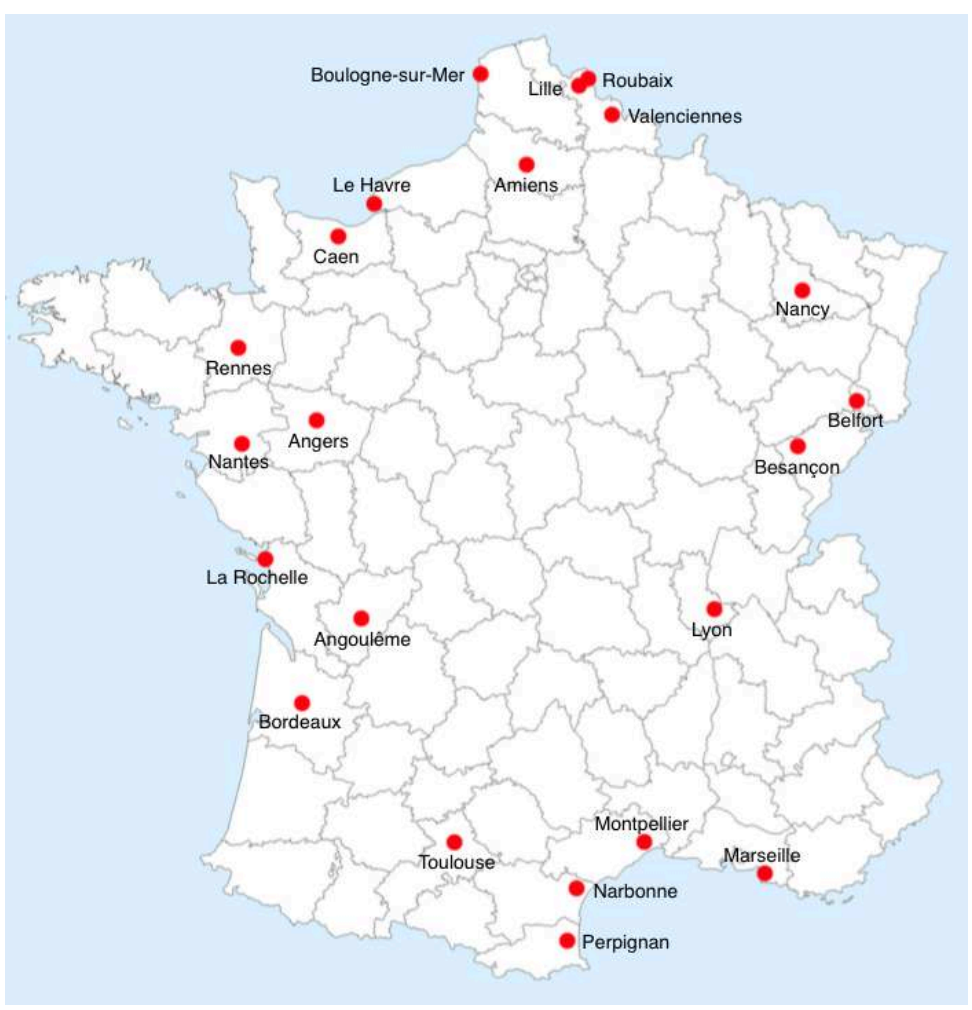

Sociétés de concerts symphoniques subventionnées par l'État entre 1881 et 1914

L'étude des montants et celle des dates extrêmes permettent de comparer les sociétés de concerts françaises avant la Première Guerre mondiale et d'en dresser une cartographie. Comprises entre 50 francs et 8000 francs, les subventions de l'État entre 1881 et 1914, une période sans inflation, sont très variées. Elles prennent naturellement en compte l'activité et les besoins des sociétés même s'il est impossible d'identifier les critères retenus. Dans cet ensemble, les sociétés dont les subventions ont atteint un montant au moins égal à 1000 francs apparaissent comme les principales sociétés de concerts françaises en dehors de Paris avant la Première Guerre mondiale. Y figurent la Société des concerts populaires d'Angers, la Société de Sainte-Cécile de Bordeaux, la Société des concerts populaires de Lille, la Société des grands concerts de Lyon, l'Association artistique des concerts classiques de Marseille, les Concerts du conservatoire de Nancy, l'Association nantaise des grands concerts (Nantes), la Société des concerts de Rennes et la Société des concerts du conservatoire de Toulouse.

Plus généralement, le subventionnement des sociétés de concerts se caractérise par une forte disparité confirmée par un document rédigé peu avant $1914^{49}$. Les Concerts populaires des départements répertoriés y sont au nombre de douze dans les villes d'Angers, Angoulême, Bordeaux, Le Havre, Lille, Lyon, Marseille, Nancy, Nantes, Rennes, Roubaix et Toulouse ${ }^{50}$. Outre quelques appréciations générales sur les sociétés, ce document indique le montant de la subvention de l'État et le nombre des concerts 
donnés par saison. Si, à Angoulême, la subvention équivaut à 42 francs par concert, elle atteint 666 francs à Lille. Cette forte différence ne doit pas dissimuler le fait que, même lorsqu'elles sont abondamment dotées, les sociétés de concerts ne peuvent considérer les subventions de l'État autrement que comme un complément. Et si l'apport financier est apprécié, c'est davantage la reconnaissance de l'État qui est recherchée.

La faiblesse des moyens distribués nous conduit effectivement à nous interroger sur le rôle de ces subventions et à nous demander si elles sont indispensables aux sociétés départementales qui les perçoivent. S'agissant de l'Association artistique d'Angers, la subvention de 300 francs qu'elle reçoit en 1878 représente $0,6 \%$ de ses recettes, celle de 4000 francs $7,2 \%$ l'année suivante et celle de 5000 francs $15 \%$ en 1881 . Cette dernière proportion, assez exceptionnelle en fait, n'est certes pas négligeable, mais force est de constater que la subvention de l'État n'a joué aucun rôle dans la fondation de l'Association artistique d'Angers. Elle n'est pas déterminante pour l'existence de la société mais permet d'en augmenter le nombre des concerts au cours de la saison. Tout autant, sinon plus, c'est la possibilité d'en faire état sur les affiches et programmes de salle qui motive les dirigeants de la Société à solliciter l'État. C'est pourquoi ils font ajouter sur le programme du concert prévu trois jours après la décision d'attribuer 300 francs à la Société en 1878, la mention "Subventionnée par le Ministre de l'Instruction publique et des Beaux-arts». En fait, cette mention est une caution dont on trouverait peut-être dans le statut de succursale du conservatoire l'équivalent dans le domaine de l'enseignement musical ${ }^{51}$. L'État cautionne des sociétés qu'il considère méritantes sans associer ce parrainage à un engagement financier significatif et déterminant. Les demandes adressées à l'administration des Beaux-arts confirment cette orientation. Fondateur de l'Association symphonique de l'école nationale de musique de Roubaix, Julien Koszul demande «une petite somme, à titre d'encouragement ", en précisant que "ce serait un grand stimulant pour les musiciens et un argument puissant auprès de l'administration municipale ${ }^{52}$.»Plus qu'un soutien financier indispensable à la survie de la société, Koszul a besoin d'une reconnaissance institutionnelle qu'il pourra faire valoir auprès des autorités municipales lorsqu'il sollicitera leur concours pécuniaire dans des proportions qu'il espère bien plus larges.

\section{La structuration progressive du protocole de subventionnement et l'intervention des inspecteurs de l'enseignement musical}

28 La pratique consistant à s'adresser directement à l'administration des Beaux-arts pour réclamer une aide, comme le fait Koszul en 1895, est la plus courante. Cependant, la multiplication des demandes pousse les autorités à définir progressivement un protocole d'attribution qui semble se mettre en place au moment où est créé l'article "décentralisation artistique ». De fait, en 1903, probablement pour la première fois, Koszul associe à sa demande des informations qui lui ont visiblement été réclamées : recettes, dépenses et programmes de la saison précédente, composition de l'orchestre, montant de la subvention municipale, règlement de la société. Dans le même temps, le directeur des Beaux-arts adresse au préfet du département du Nord un formulaire préimprimé afin de recueillir son avis sur la demande. L'attribution de la subvention est désormais assujettie au respect de ce protocole tandis que l'avis du préfet peut en influencer le montant ${ }^{53}$. La démarche poursuivie par Koszul à Roubaix est identique pour Bernard Crocé-Spinelli à Toulouse la même année $1903^{54}$. Elle reste en vigueur au moins jusqu'à la Première Guerre mondiale, laissant à l'administration toute lattitude 
pour effectuer la répartition des crédits votés par le parlement avec le concours, il est vrai, des inspecteurs de l'enseignement musical.

Avant même la création du corps des inspecteurs de l'enseignement musical en 1884, un inspecteur des Beaux-arts joue un rôle déterminant dans le subventionnement des sociétés de concerts des départements. Il ne s'agit pas d'Henri Reber ou d'Ernest Reyer, inspecteurs des succursales du conservatoire de 1871 à 1880 pour le premier et de 1881 à 1884 pour le second, mais d'Armand Gouzien, nommé inspecteur des Beaux-arts dans les départements et commissaire du gouvernement auprès des théâtres nationaux en $1880^{55}$. Avant même cette date, son action en faveur de l'Association artistique d'Angers avait été déterminante. Présent à Angers le 4 novembre 1877 pour le concert inaugural de la société, il en fut l'un des membres honoraires fondateurs ${ }^{56}$.

L'histoire du subventionnement des sociétés de concerts est parallèle à celle du corps des inspecteurs de l'enseignement musical ${ }^{57}$. Alors que le contrôle des succursales du conservatoire dans les départements est assumé par un inspecteur unique depuis $1842^{58}$, un arrêté du 28 janvier 1884 procède à son remplacement par « neuf inspecteurs de l'enseignement de la musique dans les succursales du conservatoire, les écoles nationales et dans les maîtrises ${ }^{59}$. » Un arrêté du 17 mai 1884 modifie la composition de cet ensemble désormais constitué d'un inspecteur général et de six inspecteurs dont les noms ne sont cependant pas mentionnés ${ }^{60}$. Même si elle est soumise à quelques incertitudes ${ }^{61}$, la liste des membres du corps des inspecteurs de l'enseignement musical en 1884 et 1914 peut être établie: Ernest Reyer (1884-1909) remplacé par Alfred Bruneau (1909-1932) (inspecteurs généraux) ; Ernest Guiraud (1884-1892) remplacé par Gabriel Fauré (1892-1905); Théodore Dubois (1884-1896), non remplacé ; Charles Lenepveu (1884-1910) remplacé par Paul Dukas (1910-1934); Victorin de Joncières (1884-1904) remplacé par André Gédalge (1904-1926); Henri Maréchal (1884-1921); Gustave Canoby (1884-1903) remplacé par Paul Véronge de La Nux (1903-1928 ?). Même si les deux arrêtés de 1884 n'en font pas état et limitent leur champ d'intervention aux succursales du conservatoire, les inspecteurs sont aussi chargés de superviser les sociétés de concerts.

31 Cette mission semble venir s'ajouter à la fonction officielle des inspecteurs très rapidement après la création de leur corps en 1884 . On en relève les traces dans les archives, sans présager qu'elles soient les premières, dès 1889. C'est le cas à Roubaix où des rapports d'inspection sont évoqués par Julien Koszul pour justifier sa demande de subvention ${ }^{62}$. Le rapport que Gustave Canoby consacre à l'Association symphonique de l'école nationale de musique de Roubaix le 28 février 1896 est représentatif du genre ${ }^{63}$. Le ton est bienveillant et l'objectif est avant tout de soutenir les efforts en faveur de la musique symphonique déployés par les musiciens. Les inspecteurs recommandent l'attribution, le maintien ou l'augmentation des encouragements pécuniaires de l'État. Du reste, les sociétés de concerts sont les premières à réclamer la visite d'un inspecteur qu'elles considèrent comme un honneur. La présence d'André Gédalge au concert de l'Association symphonique de l'école nationale de musique de Roubaix du 15 mai 1904 est ainsi mentionnée sur le programme de salle ${ }^{64}$. À partir de cette époque, les inspections deviennent régulières et officielles. Le périodique fondé en 1901 par Jules Combarieu, La Revue musicale, s'en fait l'écho et annonce les déplacements des inspecteurs sans indiquer néanmoins ses sources. Ainsi, apprend-on dans la livraison du $1^{\text {er }}$ février 1904 que : 
l'inspection des Grands Concerts populaires s'effectuera de la façon suivante pour

l'année 1904 :

M. Maréchal, Marseille et Nancy ;

M. Gédalge, Lille ;

M. Fauré, Angers ;

M. Lenepveu, Bordeaux ${ }^{65}$.

32 dans le processus de subventionnement des sociétés de concerts et une mission des inspecteurs de l'enseignement musical aussi importante que celle des succursales du Conservatoire. Amenés à se déplacer sur l'ensemble du territoire, et non pas uniquement dans les villes dotées d'une école conventionnée, les inspecteurs acquièrent une vision globale de l'univers symphonique français et la possibilité d'en établir une hiérarchie. C'est ainsi que, dans son rapport du $1^{\text {er }}$ mai 1911, de retour de la ville rose, André Gédalge peut écrire : « la Société des concerts de Toulouse m'a paru, et de beaucoup, la meilleure et la plus intéressante de celles que j'ai entendues jusqu'ici en province $^{66}$. $»$ Ce jugement le conduit à réclamer de la part de l'État un engagement financier plus important que celui qu'il apporte à d'autres sociétés d'une qualité jugée moindre.

\section{Élan brisé et difficile retour à la normale (1914-1929)}

La Première Guerre mondiale vient mettre un coup d'arrêt au processus hésitant mais néanmoins réel du subventionnement de la musique en France. Le lent retour à la normale s'opère parallèlement à l'émergence de trois inventions susceptibles d'influencer considérablement la vie musicale en général et celle des orchestres en particulier: l'enregistrement électrique (qui annonce une large diffusion des phonographes et des disques 78 tours), la radiodiffusion et le cinéma parlant. La brutale crise économique qui commence en 1929 vient déstabiliser encore plus un secteur en pleine convalescence ${ }^{67}$.

\section{L'effondrement de la Première Guerre mondiale}

Les hommes partis au front, les orchestres - très peu ou pas du tout féminisés - sont obligés d'interrompre leurs activités pendant une période plus ou moins longue. C'est notamment le cas de la Société des concerts populaires d'Angers et de la Société des concerts de Toulouse qui ne donnent aucun concert entre 1914 et 1918. Ces deux renoncements provisoires sont l'expression de la baisse et de la faiblesse de l'activité symphonique pendant la Première Guerre mondiale sur l'ensemble du territoire français. Pour sa part, l'État se montre moins généreux et plus soucieux de concentrer les deniers publics vers l'effort de guerre. Les documents budgétaires et les archives portent la trace - ou plus exactement l'inverse - de ce déclin brutal. Aussi, alors qu'il était réalisable de manière presque exhaustive pour la période antérieure à la guerre, le recensement des sociétés de concerts françaises subventionnées entre 1914 et 1918 devient impossible. Il faut en revenir aux chiffres globaux publiés par Myriam Chimènes. Le budget de la musique passe de 165500 francs en 1914 à 49900 francs en 1918. La chute est d'autant plus brutale que les deux sociétés de concerts institutionnalisées, Colonne et Lamoureux, conservent chacune la subvention de 15000 francs qu'elles recevaient avant guerre. Doté de 46000 francs en 1914, l'article

Transposition, 7| 2018 
"Concerts populaires et sociétés musicales à Paris et dans les départements et œuvres de décentralisation artistique » est réduit à 7500 francs en 1918. Dans le même temps, celui consacré à la décentralisation passe de 74000 francs à 5400 francs. Les deux articles dédiés au subventionnement des concerts subissent ensemble une diminution de près de $90 \%$ entre 1914 et 1918 . Elle traduit tout autant la volonté de l'État de financer prioritairement la guerre que la réduction du nombre de sociétés actives prêtes à solliciter des aides. C'est ce que confirme un document d'archives de 1918 sur lequel le nom des principales sociétés subventionnées est suivi de la mention " n'a pas reçu depuis $1914^{68}$. $"$ En outre, le chapitre des grands concerts se voit doter d'une nouvelle mission, celle de la propagande artistique à l'étranger («Subventions aux œuvres de propagande théâtrale à l'étranger $»)^{69}$.

\section{Un retour à la normale difficile}

Il faut attendre 1920 pour retrouver les traces d'un financement dans des proportions identiques à 1913 . De plus, du seul point de vue quantitatif, il évolue peu jusqu'en 1928 : 12 sociétés de concerts symphoniques se partagent 20400 francs en 1920 ; elles sont 17 à se voir attribuer globalement 23800 francs en 1928. Tous les orchestres existants au moment du déclenchement de la guerre ne sont pas en mesure de se reconstituer ou de redéployer une activité justifiant l'octroi d'une subvention de l'État ${ }^{70}$. C'est notamment le cas de la Société des auditions classiques d'Amiens, la Société philharmonique de Belfort, la Société de Sainte-Cécile et l'Association artistique des concerts populaires du Havre, l'Association nantaise des grands concerts, la Société des concerts populaires de Narbonne et la Société des concerts de Rennes. D'autres formations, souvent plus anciennes et dotées de subventions plus importantes, reprennent leurs activités à l'image de la Société des concerts populaires d'Angers, la Société de Sainte-Cécile de Bordeaux, la Société des concerts populaires de Lille, la Société des grands concerts de Lyon, l'Association artistique des concerts classiques de Marseille, les Concerts du conservatoire de Nancy, l'Association symphonique des concerts du conservatoire de Roubaix, la Société des concerts du conservatoire de Toulouse et la Société des concerts du conservatoire de Valenciennes. Dans le même temps, quelques sociétés nouvelles sont adoubées par l'État : la Société des concerts du conservatoire de Metz, une ville qui a réintégré la France à l'issue du conflit mondial, la Société des concerts du conservatoire de Rennes (1897) qui prend la place de la Société des concerts fondée dans cette ville en 1874 et la Société des concerts du conservatoire de Toulon (1906).

On remarquera que ces sociétés nouvellement subventionnées, même si elles ne viennent pas toutes de voir le jour, ont délaissé l'appellation autrefois si courante de " concerts populaires". L'abandon de cette expression devenue désuète est moins le signe d'un renoncement qu'un constat qui s'impose à tous, celui de l'impérieuse nécessité de penser le concert pour un public le plus large possible. Dans ce processus l'année 1930 occupe une place importante puisque l'État fait lui aussi disparaître l'expression de son budget: le chapitre "Concerts populaires à Paris et dans les départements et œuvres de décentralisation artistique " est rebaptisé "Concerts à Paris et dans les départements, musiques populaires et œuvres de décentralisation artistique ». 


\begin{tabular}{|c|c|c|c|c|}
\hline Ville & Nom de la société & $\begin{array}{l}\text { Date de la } \\
\text { fondation }\end{array}$ & $\begin{array}{l}\text { Dates extrêmes } \quad \text { du } \\
\text { subventionnement sur } \\
\text { la période étudiée }\end{array}$ & $\begin{array}{l}\text { Montant minimal } \\
\text { et maximal de la } \\
\text { subvention (en } \\
\text { francs) }\end{array}$ \\
\hline Angers & $\begin{array}{l}\text { Société des concerts } \\
\text { populaires }\end{array}$ & 1877 & $1920-1929$ & $4000 / 7000$ \\
\hline Angoulême & $\begin{array}{l}\text { Société des concerts } \\
\text { populaires }\end{array}$ & & $1920-1923$ & 300 \\
\hline Besançon & $\begin{array}{l}\text { Société des concerts } \\
\text { symphoniques }\end{array}$ & 1907 & $1920-1929$ & $300 / 500$ \\
\hline Bordeaux & $\begin{array}{l}\text { Société de Sainte- } \\
\text { Cécile }\end{array}$ & 1843 & $1920-1929$ & $2500 / 5000$ \\
\hline Caen & $\begin{array}{l}\text { Concerts populaires } \\
\text { de l'école nationale } \\
\text { de musique** }\end{array}$ & & $1923-1929$ & $200 / 500$ \\
\hline Calais* & Société Éolienne** & & $1926-1929$ & $200 / 1000$ \\
\hline Carcassonne* & $\begin{array}{l}\text { Association } \\
\text { symphonique des } \\
\text { concerts** }\end{array}$ & 1901 & $1927-1929$ & $150 / 200$ \\
\hline Dijon* & $\begin{array}{l}\text { Société des concerts } \\
\text { du conservatoire }\end{array}$ & & $1920-1929$ & $1000 / 3500$ \\
\hline La Rochelle & $\begin{array}{l}\text { Société } \\
\text { philharmonique** }\end{array}$ & 1815 & 1929 & 1000 \\
\hline Lille & $\begin{array}{l}\text { Société des concerts } \\
\text { populaires }\end{array}$ & 1877 & $1920-1929$ & $2500 / 5000$ \\
\hline Lyon & $\begin{array}{l}\text { Société des grands } \\
\text { concerts }\end{array}$ & 1905 & $1920-1929$ & $3500 / 5000$ \\
\hline Marseille & $\begin{array}{lr}\text { Association } & \text { artistique } \\
\text { des } & \text { concerts } \\
\text { classiques } & \end{array}$ & 1886 & $1920-1924$ & $500 / 5000$ \\
\hline Metz* & $\begin{array}{l}\text { Société des concerts } \\
\text { du conservatoire }\end{array}$ & & $1925-1929$ & $100 / 3000$ \\
\hline Nancy & $\begin{array}{l}\text { Concerts } \mathrm{du} \\
\text { conservatoire }\end{array}$ & 1884 & $1920-1929$ & $2000 / 5000$ \\
\hline Rennes & $\begin{array}{l}\text { Société des concerts } \\
\text { du conservatoire }\end{array}$ & 1897 & $1920-1929$ & $500 / 5000$ \\
\hline
\end{tabular}




\begin{tabular}{|c|c|c|c|c|}
\hline Roubaix & $\begin{array}{l}\text { Association } \\
\text { symphonique de } \\
\text { l'école nationale de } \\
\text { musique }\end{array}$ & 1889 & $1920-1929$ & $250 / 3500$ \\
\hline Thouars* & $\begin{array}{l}\text { Société des } \\
\text { concerts }\end{array}$ & 1921 & 1929 & 300 \\
\hline Toulon* & $\begin{array}{l}\text { Société des concerts } \\
\text { du conservatoire }{ }^{* *}\end{array}$ & 1906 & $1920-1929$ & $200 / 1000$ \\
\hline Toulouse & $\begin{array}{l}\text { Société des concerts } \\
\text { du conservatoire }\end{array}$ & 1902 & $1920-1929$ & $2000 / 5000$ \\
\hline Tourcoing* & $\begin{array}{l}\text { Société des concerts } \\
\text { du conservatoire }{ }^{* *}\end{array}$ & & 1929 & 2000 \\
\hline Valenciennes & $\begin{array}{l}\text { Société des concerts } \\
\text { du conservatoire }\end{array}$ & 1913 & $1920-1929$ & $250 / 2500$ \\
\hline
\end{tabular}

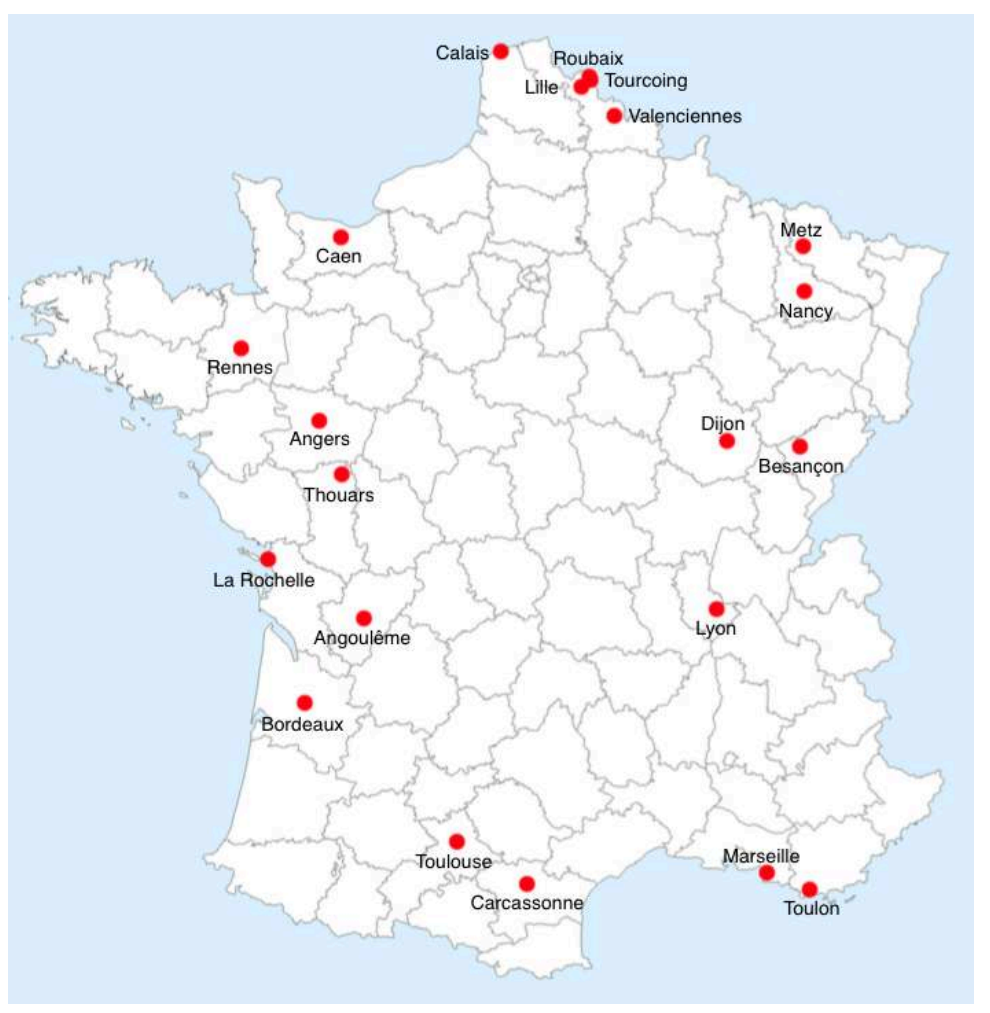

Sociétés de concerts symphoniques subventionnées par l'État entre 1920 et 192971

Presque insignifiant, l'engagement pécuniaire de l'État conserve le principe de la caution ou de l'adoubement jusqu'en 1929. Le rédacteur d'une note évoque même à la fin de la décennie "un simple encouragement moral ${ }^{72}$ ». Il est vrai que la subvention accordée à la Société des concerts du conservatoire de Toulouse en 1921 ne représente que 3,5\% de ses recettes ${ }^{73}$ et que celle de la Société des concerts du conservatoire de Valenciennes atteint uniquement $2,2 \%$ ! La situation est d'autant plus problématique que l'État donne d'une main ce qu'il récupère de l'autre à travers des taxes dont le 
poids grandissant est dénoncé. Aymé Kunc, directeur de la Société des concerts du conservatoire de Toulouse, les évalue à 5000 francs pour la saison 1920-1921, soit le double de la subvention accordée par l'État qui, au demeurant, n'est pas le seul en cause $^{74}$.

Comme l'ensemble des spectacles, les concerts sont associés à trois taxes différentes : le droit des pauvres, la taxe d'État, la taxe municipale ${ }^{75}$. L'ancestral droit des pauvres est encore en vigueur même si le prélèvement de $10 \%$ de la recette initialement mentionné dans la loi du 7 frimaire an V [27 novembre 1796] a été réduit à partir de 1876, date à partir de laquelle l'ensemble des taxes ne peut excéder $5 \%$ des recettes. Instaurée par la loi du 30 décembre 1916, la taxe d'État dite «taxe de guerre » a été maintenue et prévoie le prélèvement de $5 \%$ du prix net des places (c'est-à-dire déduction faite de toutes les autres taxes). Enfin, la troisième taxe est municipale, les communes étant autorisées depuis 1920 à prélever une taxe sur les spectacles ne pouvant excéder $50 \%$ de l'impôt d'État. Problématique nouvelle, les taxes constituent pour les sociétés de concerts une contrainte supplémentaire dans un environnement particulièrement difficile, alors que les aides de l'État restent symboliques. Cependant, à partir de 1930, l'État va s'impliquer davantage dans ce secteur et mettre en place une commission spécifiquement dédiée à l'attribution des subventions aux sociétés de concerts.

\section{Le temps de la Commission des concerts (1930-1967)}

\section{Naissance et genèse de la Commission des concerts}

L'instauration, en 1930, d'un organisme consultatif dédié à la musique, dont le modèle pourrait être le Conseil supérieur des Beaux-arts créé en $1875^{76}$, est l'aboutissement d'un processus déjà ancien ${ }^{77}$. Sans remonter au comité souhaitant instaurer un théâtre lyrique départemental en $1888^{78}$, on peut notamment évoquer «la Commission consultative instituée auprès du sous-secrétariat d'État des Beaux-arts, en vue d'examiner les mesures à prendre pour favoriser les intérêts de l'art dramatique et lyrique et le développement des théâtres populaires» en $1905^{79}$. Son action ne semble guère se prolonger au delà d'une année ${ }^{80}$. La longévité de la « commission consultative chargée de donner son avis sur la répartition et les encouragements affectés par le budget des Beaux-arts à la décentralisation musicale, à l'occasion des représentations dans les théâtres des départements, d'œuvres lyriques de compositeurs français n'ayant pas encore été joué » semble identique. Instaurée par un arrêté du 23 mai $1912^{81}$, elle réunit un compositeur, un inspecteur général de l'enseignement musical, des parlementaires, des membres de l'administration du sous-secrétariat des Beaux-arts, des représentants de la Société des auteurs et compositeurs dramatiques [SACD]. Le rapport rédigé à la veille de la Première Guerre mondiale par deux membres de cette commission, le compositeur Xavier Leroux et l'auteur et critique dramatiques Adolphe Aderer (membre de la Commission de la SACD), n'aura guère laissé de traces dans la vie musicale française ${ }^{82}$. Moins focalisées sur le théâtre lyrique et plus ambitieuses sont les tentatives prises une fois la paix revenue.

L'instauration le 8 novembre 1928 de la Commission pour la rénovation et le développement des études musicales témoigne de la volonté de l'État de faire participer l'ensemble des acteurs de la vie musicale à la réflexion sur sa propre action ${ }^{83}$. Rassemblant soixante-dix-neuf membres, cette commission présente ses conclusions, le 
8 janvier 1931, sous la forme d'un long rapport rédigé par son secrétaire général, l'inspecteur de l'instruction publique Charles L'Hôpital ${ }^{84}$. Catalogue d'intentions et synthèse des souhaits du monde musical (interprètes, compositeurs, enseignants, facteurs d'instruments, éditeurs, organisateurs de spectacles), ce rapport apparaît comme un état des lieux sur lequel pourraient reposer la définition d'une véritable politique musicale. Émanation de la commission, le Comité national de propagande pour la rénovation et le développement de la musique (rebaptisé Comité national de propagande pour la musique en 1930) fera de ce rapport une sorte de programme dont les propositions seront préconisées, et parfois adoptées, au cours des années 1930 et 1940. C'est dans le contexte des travaux de la Commission pour la rénovation et le développement des études musicales qu'est créée une commission consultative au sein même du sous-secrétariat d'État des Beaux-arts.

Instaurée par un arrêté du 15 mars 1930, la "commission consultative chargée de donner son avis sur la répartition du crédit inscrit au budget des Beaux-arts sous la rubrique "Décentralisation lyrique " (subventions à des théâtres des départements à l'occasion de la représentation d'œuvres lyriques, non encore jouées, de compositeurs français)" est rapidement amenée à se prononcer sur des questions touchant un domaine plus large que celui du seul opéra. C'est pourquoi elle est remplacée par la Commission consultative des concerts et de la décentralisation artistique par un arrêté du 21 janvier 1932. Les attributions de cette commission sont beaucoup plus larges puisque elle est chargée de donner son avis "sur la répartition des crédits inscrits au budget des Beaux-arts en faveur des sociétés de concerts et des œuvres de décentralisation artistique (grandes sociétés musicales à Paris et dans les départements, œuvres de décentralisation artistique, théâtre de plein air et décentralisation lyrique) », mais aussi, « sur toutes les questions qui lui sont soumises par l'administration des Beaux-arts. » Pour la première fois, une commission a pour mission de donner son avis sur toutes les questions liées à la musique et non plus seulement sur celles du seul théâtre lyrique.

La redéfinition de la commission consultative entre 1930 et 1932 doit beaucoup à la question des subventions aux sociétés de concerts françaises. La loi de finances du 16 avril 1930 ayant assujetti la délivrance des subventions aux sociétés de concerts à l'existence de cahier des charges, un groupe de travail est mis en place par le directeur général de l'administration des Beaux-arts. La clause du cahier des charges étant déjà imposée aux sociétés de concerts institutionnalisées depuis 1897, il est par conséquent question de l'étendre à toutes les formations en activité sur le territoire français ${ }^{85}$. Le constat est néanmoins fait qu'une telle obligation n'est pas envisageable compte tenu de la faiblesse des subventions accordées aux sociétés de concerts. En revanche, il est décidé d'imposer à toutes les sociétés souhaitant obtenir un subside de l'État d'avoir à leur tête un chef d'orchestre de nationalité française et de ne pas compter plus de $5 \%$ de musiciens étrangers. Par ailleurs, "aux plus importantes, et aux mieux dotées (notamment les sociétés des concerts de conservatoires) on imposera d'inscrire au programme un quart au moins de musique française ${ }^{86}$. Alors que l'attribution des subventions reposait uniquement sur les évaluations qualitatives des inspecteurs et le caractère populaire du projet artistique, elle dépend désormais de considérations prioritairement idéologiques et corporatives: la musique et les musiciens français d'abord. Ce nationalisme musical institutionnalisé, qui voit le jour au début des années 1930 sous la pression de compositeurs et de représentants des principales sociétés de concerts ${ }^{87}$, restera une priorité pendant plus de trois décennies. Les 
discussions du groupe de travail se concrétisent par la rédaction de l'arrêté du 20 août 1931 « instaurant les conditions auxquelles est subordonnée l'attribution éventuelle d'une subvention par l'administration des Beaux-arts aux Sociétés de concerts $^{88}$. " Il présente les deux clauses (nationalité française du chef d'orchestre et d'un minimum de $95 \%$ des instrumentistes; un quart de musique française dans les programmes) comme des conditions d'admission incontournables avant de dresser la liste des documents devant accompagner la demande transmise par le préfet ${ }^{89}$. L'arrêté du 20 août 1931 est adressé aux sociétés de concerts susceptibles de solliciter une subvention et devient la pièce centrale du dispositif.

Étant désormais admis que la question des sociétés de concerts et celle de leur subventionnement avaient pris une place importante dans la politique musicale de l'État, la commission consultative instaurée le 15 mars 1930 ne pouvait qu'être redéfinie et voir son champ d'intervention élargi. Ce sera chose faite le 21 janvier 1932. Sa composition est elle aussi révisée. Présidée par le directeur général des Beaux-arts, elle réunit le directeur du Conservatoire, l'inspecteur général et les inspecteurs de l'enseignement musical, le chef du bureau des théâtres, l'administrateur de la ComédieFrançaise, le directeur de l'Odéon, le président ou un représentant de la SACD, Alfred Bachelet (directeur du conservatoire de Nancy, membre de l'Institut), Gustave Charpentier (membre de l'Institut), Adolphe Boschot (critique musical et membre de l'Institut), Romain Coolus (auteur dramatique), Maurice Donnay (de l'académie française), Georges Hue (membre de l'Institut), Pierre Lalo (critique musical et membre $\mathrm{du}$ conseil supérieur de l'enseignement du conservatoire), Charles-Marie Widor (secrétaire perpétuel de l'académie française). Malgré ses compétences en matière de décentralisation, seul l'un de ses membres, bien que né à Paris, Alfred Bachelet, peut être considéré comme un représentant des sociétés de concerts des régions.

\section{Les premiers pas de la Commission}

Résultant d'une meilleure prise en compte de la musique par l'État, la naissance de la Commission des concerts voit néanmoins le jour dans un contexte anxiogène, celui de la généralisation de l'enregistrement électrique facilitant et améliorant la production des disques, de l'inexorable essor de la radio et du cinéma sonorisé, mais aussi de la crise économique dont les effets se font sentir dès le début de la décennie. La grande enquête menée en 1930 par Le Courrier musical est l'une des manifestations des craintes qui frappent le secteur musical. Des dizaines de réponses émanant de compositeurs, instrumentistes, organisateurs de concerts, élus et parlementaires, sont publiées sur pas moins de dix-sept pages ${ }^{90}$. Deux articles plus développés sont publiés dans des livraisons ultérieures. Ils sont signés Raymond Charpentier ${ }^{91}$ et Pierre Lalo ${ }^{92}$. Pour ce dernier, les causes sont spirituelles et matérielles mais des remèdes sont envisageables, notamment en augmentant les subventions de l'État. Dans une note de l'administration des Beaux-arts, le constat est fait que "beaucoup de sociétés, surtout dans les départements, auraient déjà dû disparaître si elles n'avaient le secours des libéralités privées ${ }^{93}$.»

Il n'est pas certain que l'activité de la Commission des concerts soit déterminante pour les sociétés de concerts des régions devant surmonter les difficultés financières qu'elles rencontrent. Dans la pratique, le rôle des inspecteurs de l'enseignement musical reste prédominant et c'est le premier d'entre eux, Alfred Bruneau, du moins jusqu'à son 
décès en 1934, qui soumet des propositions aux membres de la Commission ${ }^{94}$. Néanmoins, même si ces derniers n'y apportent que de légères modifications, il n'empêche que la répartition est validée par un collège d'experts et peut être perçue comme le classement annuel des sociétés de concerts. Connaissant mal les sociétés des régions, les membres de la Commission se montrent plus intéressés par les sociétés parisiennes et plus encore par la redéfinition permanente de leur cahier des charges. De leur côté, les sociétés se conforment aux directives contenues dans l'arrêté du 20 août 1931. Elles adressent à l'administration des Beaux-arts, par la voie préfectorale, les documents et informations demandés. La nationalité des musiciens et l'origine nationale des œuvres interprétées y figurent en bonne place. Le premier point ne semble guère poser de problème. Ainsi, à Saint-Étienne, tous les membres de l'orchestre de l'Association des concerts du conservatoire sont français à l'exception d'un italien et d'un russe. À Toulouse, ils sont tous français. En ce qui concerne les œuvres interprétées, certaines sociétés semblent s'inspirer des pratiques adoptées dans la capitale en conformité avec le cahier des charges des sociétés institutionnalisées. C'est le cas à Saint-Étienne où les programmes des concerts de la saison 1932-1933 comportent six heures et trente et une minutes de musique française sur un total de dix heures et quinze minutes, soit une proportion des deux tiers bien supérieure à celle imposée - un quart ${ }^{95}$. Certains dirigeants de société se livrent à des classements par écoles nationales. C'est le cas de Fernand Lamy à Valenciennes dont la liste des œuvres exécutées pendant la saison 1931-1932 comporte quatre sections : école française, école allemande, école russe, école diverses. Au cours de la saison suivante, les écoles sont trois : française, allemande et belge. Dans les deux cas, seule l'école allemande ne compte que des compositeurs décédés ${ }^{96}$. Outre ses conséquences sur la programmation des sociétés de concerts, l'arrêté du 20 août 1931 impose une vision de l'histoire de la musique qui ne saurait se décliner autrement que sous la forme d'écoles nationales indépendantes les unes des autres et au sein desquelles la française serait privilégiée.

La crise que traversent les orchestres, l'intérêt croissant de l'État pour le concert, l'instauration d'une commission dédiée à la musique instrumentale et l'ambition culturelle du gouvernement de Front populaire à partir de 1936 s'accompagnent d'une augmentation significative des subventions accordées aux sociétés des régions. Sensible en 1929, elle se confirme puis s'amplifie tant du point de vue du nombre de sociétés que du volume financier : 17 sociétés subventionnées à hauteur de 23800 francs en 1928, 20 sociétés et 56200 francs en 1929, puis 27 sociétés et 121050 francs en 1930 avant d'atteindre 43 sociétés et 566100 francs en 1939. L'année 1940 voit naturellement ces chiffres diminuer. En une décennie, le nombre des sociétés subventionnées double tandis que le montant global des subventions est multiplié par dix en francs courants par huit en francs constants. Les sociétés les plus importantes et les plus soutenues par l'État sont les premières bénéficiaires de cette évolution: la Société des concerts populaires d'Angers ( $4200 \mathrm{~F}$ en 1928 et $56000 \mathrm{~F}$ en 1939), la Société de Sainte-Cécile de Bordeaux, qui prend le titre de Société des concerts du conservatoire en 1937 ( $2700 \mathrm{~F}$ $35000 \mathrm{~F})$, la Société des concerts du conservatoire de Dijon (2 $700 \mathrm{~F}-18000 \mathrm{~F})$, la Société des grands concerts de Lyon, rebaptisée Association philharmonique en 1938 (3800 F - 35000 F), la Société des concerts du conservatoire de Nancy (2600 F $56000 \mathrm{~F})$, la Société des concerts du conservatoire de Rennes (600 F- $20000 \mathrm{~F})$, l'Association symphonique de l'école nationale de musique de Roubaix (500 F$20000 \mathrm{~F})$, la Société des concerts du conservatoire de Toulon $(700 \mathrm{~F}-20000 \mathrm{~F})$, la Société des concerts du conservatoire de Toulouse ( $2700 \mathrm{~F}-56000$ F), la Société des 
concerts du conservatoire de Valenciennes ( $400 \mathrm{~F}-56000 \mathrm{~F}$ ). Seules manquent à l'appel la Société des concerts populaires de Lille et l'Association artistique des concerts classiques de Marseille. Trois sociétés récemment fondées prennent place dans cet ensemble : la Société des concerts du conservatoire de Metz ( $800 \mathrm{~F}-40000 \mathrm{~F})$, la Société des concerts du conservatoire d'Orléans ( $2500 \mathrm{~F}$ en $1929-40000 \mathrm{~F}$ ) et l'Association des concerts du conservatoire de Saint-Étienne ( $1000 \mathrm{~F}$ en 1930 - $40000 \mathrm{~F})$. Par ailleurs, l'augmentation du nombre de sociétés subventionnées par l'État entraîne une plus grande dissémination dans l'espace français. Entre 1930 et 1940, une vingtaine de villes supplémentaires sont recensées ${ }^{97}$ :

\begin{tabular}{|c|c|c|c|c|}
\hline Ville & Nom de la société & $\begin{array}{l}\text { Date de la } \\
\text { fondation }\end{array}$ & $\begin{array}{l}\text { Dates extrêmes du } \\
\text { subventionnement sur } \\
\text { la période étudiée }\end{array}$ & $\begin{array}{l}\text { Montant } \\
\text { minimal et } \\
\text { maximal de la } \\
\text { subvention (en } \\
\text { francs) }\end{array}$ \\
\hline Agen* & $\begin{array}{l}\text { Union symphonique } \\
\text { agenaise }^{* *}\end{array}$ & & $1933-1938$ & $100 / 1000$ \\
\hline $\begin{array}{l}\text { Aix-en- } \\
\text { Provence* }\end{array}$ & $\begin{array}{l}\text { Société des concerts de } \\
\text { l'école nationale de } \\
\text { musique** }^{*}\end{array}$ & & $1939-1940$ & 1000 \\
\hline Amiens & $\begin{array}{l}\text { Société des concerts } \\
\text { symphoniques** }\end{array}$ & 1933 & $1937-1939$ & $1000 / 2000$ \\
\hline Angers & $\begin{array}{l}\text { Société des concerts } \\
\text { populaires }\end{array}$ & 1877 & $1930-1940$ & $12000 / 56000$ \\
\hline Angoulême & $\begin{array}{l}\text { Les Amis de la } \\
\text { musique** }\end{array}$ & 1930 & $1932-1933$ & $250 / 300$ \\
\hline Bayonne* & $\begin{array}{l}\text { Association des } \\
\text { concerts Rameau** }\end{array}$ & 1931 & $1932-1938$ & $250 / 1100$ \\
\hline Besançon & $\begin{array}{l}\text { Société des concerts } \\
\text { symphoniques }\end{array}$ & 1907 & 1930-1939 & $450 / 2000$ \\
\hline Béthune* & $\begin{array}{l}\text { Section symphonique } \\
\text { du cercle de Béthune** }\end{array}$ & & $1932-1933$ & 3000 \\
\hline \multirow{3}{*}{ Bordeaux } & Société de Sainte-Cécile & 1843 & $1930-1937$ & $10000 / 21200$ \\
\hline & $\begin{array}{l}\text { Société des concerts du } \\
\text { conservatoire** }\end{array}$ & & $1938-1940$ & $30000 / 35000$ \\
\hline & $\begin{array}{l}\text { Cercle } \\
\text { philharmonique** }\end{array}$ & 1837 & $1932-1934$ & $250 / 600$ \\
\hline
\end{tabular}




\begin{tabular}{|c|c|c|c|c|}
\hline Bourges* & $\begin{array}{lr}\text { Association des } \\
\text { concerts de l'école } \\
\text { nationale de musique }\end{array}$ & 1927 & $1932-1940$ & $500 / 3680$ \\
\hline Brest* & $\begin{array}{l}\text { Orchestre de l'école } \\
\text { nationale de musique* }\end{array}$ & & $1933-1940$ & $1000 / 5800$ \\
\hline Caen & $\begin{array}{l}\text { Concerts populaires de } \\
\text { l'école nationale de } \\
\text { musique }\end{array}$ & & $1930-1940$ & $704 / 2296$ \\
\hline \multirow{3}{*}{ Calais } & Société Éolienne & & 1933 & 2000 \\
\hline & $\begin{array}{l}\text { Association des anciens } \\
\text { élèves de l'école } \\
\text { nationale de musique** }\end{array}$ & & $1932-1933$ & $2000 / 2500$ \\
\hline & $\begin{array}{l}\text { Orchestre de l'école } \\
\text { nationale de musique** }\end{array}$ & & $1935-1940$ & $1000 / 7900$ \\
\hline Châteauroux* & Cercle symphonique** & & $1930-1939$ & $550 / 1000$ \\
\hline $\begin{array}{l}\text { Clermont- } \\
\text { Ferrand* }\end{array}$ & $\begin{array}{lr}\text { Association } & \text { des } \\
\text { concerts } & d u \\
\text { conservatoire }^{* *} & \end{array}$ & & $1939-1940$ & 1000 \\
\hline Dijon & $\begin{array}{l}\text { Société des concerts du } \\
\text { conservatoire }\end{array}$ & & $1930-1940$ & $7000 / 19200$ \\
\hline Douai* & $\begin{array}{l}\text { Société des concerts } \\
\text { symphoniques du } \\
\text { conservatoire }^{* *}\end{array}$ & & $1933-1940$ & $2200 / 6800$ \\
\hline La Rochelle & $\begin{array}{l}\text { Société } \\
\text { philharmonique }\end{array}$ & 1815 & 1930 & 2000 \\
\hline Le Mans* & $\begin{array}{l}\text { Société des concerts du } \\
\text { conservatoire }^{* *}\end{array}$ & & $1933-1940$ & $2000 / 6000$ \\
\hline Lille & $\begin{array}{l}\text { Société des concerts } \\
\text { populaires }\end{array}$ & 1877 & $1930-1940$ & $1000 / 10000$ \\
\hline Limoges* & $\begin{array}{l}\text { Société des concerts du } \\
\text { conservatoire }^{* *}\end{array}$ & & $1938-1940$ & $2000 / 3000$ \\
\hline Lorient* & $\begin{array}{l}\text { Société des concerts de } \\
\text { l'école de musique** }\end{array}$ & & $1933-1940$ & $1400 / 5680$ \\
\hline & $\begin{array}{l}\text { Société des grands } \\
\text { concerts / Association } \\
\text { philharmonique (1938) }\end{array}$ & 1905 & $1930-1940$ & $10000 / 35000$ \\
\hline
\end{tabular}




\begin{tabular}{|c|c|c|c|c|}
\hline & $\begin{array}{l}\text { Trigentuor } \\
\text { instrumental } \\
\text { lyonnais**98 }\end{array}$ & 1925 & $1932-1939$ & $600 / 3400$ \\
\hline Marseille & $\begin{array}{l}\text { Association artistique } \\
\text { des concerts classiques }\end{array}$ & 1886 & $1932-1940$ & $1500 / 10000$ \\
\hline \multirow{2}{*}{ Metz } & $\begin{array}{l}\text { Société des concerts du } \\
\text { conservatoire }\end{array}$ & & $1930-1940$ & $8000 / 40000$ \\
\hline & $\begin{array}{l}\text { Société des concerts } \\
\text { Soudant** }\end{array}$ & & $1932-1939$ & $100 / 1600$ \\
\hline Montpellier* & $\begin{array}{l}\text { Société des amateurs } \\
\text { de musique** }\end{array}$ & & 1939-1939 & $100 / 1000$ \\
\hline \multirow{2}{*}{ Nancy } & $\begin{array}{l}\text { Concerts } \\
\text { conservatoire }\end{array}$ & 1884 & $1930-1940$ & $10000 / 56000$ \\
\hline & $\begin{array}{l}\text { Orchestre } \\
\text { symphonique }^{* *}\end{array}$ & & $1932-1933$ & $500 / 600$ \\
\hline Nantes & $\begin{array}{lr}\text { Association } & \\
\text { symphonique des } \\
\text { concerts } & \text { du } \\
\text { conservatoire } & \end{array}$ & 1938 & $1938-1940$ & $1000 / 3000$ \\
\hline Narbonne & $\begin{array}{l}\text { Symphonie amicale de } \\
\text { Narbonne** }\end{array}$ & & $1932-1934$ & $250 / 300$ \\
\hline Nîmes* & $\begin{array}{l}\text { Société des concerts du } \\
\text { conservatoire** }\end{array}$ & & $1933-1940$ & $1000 / 5800$ \\
\hline \multirow{2}{*}{ Orange* } & $\begin{array}{l}\text { Orchestre } \\
\text { symphonique } \\
\text { d'Orange }^{* *}\end{array}$ & & $1930-1939$ & $100 / 1100$ \\
\hline & $\begin{array}{l}\text { Symphonie } \\
\text { indépendante } \\
\text { d'Orange** }^{* *}\end{array}$ & & $1930-1932$ & 500 \\
\hline Orléans* & $\begin{array}{l}\text { Société des concerts du } \\
\text { conservatoire** }\end{array}$ & 1921 & $1930-1940$ & $2500 / 17000$ \\
\hline $\mathrm{Pau}^{*}$ & $\begin{array}{l}\text { Société des concerts du } \\
\text { conservatoire }\end{array}$ & & $1937-1940$ & $1000 / 2000$ \\
\hline Reims* & $\begin{array}{l}\text { Société des concerts de } \\
\text { l'école nationale de } \\
\text { musique }^{* *}\end{array}$ & & $1938-1940$ & $1000 / 5000$ \\
\hline Rennes & $\begin{array}{l}\text { Société des concerts du } \\
\text { conservatoire }\end{array}$ & 1897 & $1930-1940$ & $10000 / 22320$ \\
\hline
\end{tabular}




\begin{tabular}{|c|c|c|c|c|}
\hline Roubaix & $\begin{array}{l}\text { Association } \\
\text { symphonique de l'école } \\
\text { nationale de musique }\end{array}$ & 1889 & $1930-1940$ & $7000 / 22520$ \\
\hline Saint-Brieuc* & $\begin{array}{l}\text { Société } \\
\text { philharmonique** }\end{array}$ & & $1933-1940$ & $100 / 1300$ \\
\hline $\begin{array}{l}\text { Saint- } \\
\text { Étienne* }\end{array}$ & $\begin{array}{lr}\text { Association } & \text { des } \\
\text { concerts } & \text { du } \\
\text { conservatoire }^{* *} & \end{array}$ & 1930 & $1930-1940$ & $1000 / 40000$ \\
\hline Strasbourg* & $\begin{array}{l}\text { Concerts de l'église } \\
\text { Saint-Guillaume** }\end{array}$ & & $1930-1939$ & $200 / 2000$ \\
\hline Tarbes* & $\begin{array}{l}\text { Société } \\
\text { philharmonique** }\end{array}$ & & $1938-1940$ & $1300 / 3000$ \\
\hline Thouars & Société des concerts & 1921 & 1930-1934 & $400 / 500$ \\
\hline Toulon & $\begin{array}{l}\text { Société des concerts du } \\
\text { conservatoire }\end{array}$ & 1906 & $1930-1940$ & $3000 / 22400$ \\
\hline Toulouse & $\begin{array}{l}\text { Société des concerts du } \\
\text { conservatoire }\end{array}$ & 1902 & $1930-1940$ & $10000 / 56000$ \\
\hline Tourcoing* & $\begin{array}{l}\text { Société des concerts du } \\
\text { conservatoire }\end{array}$ & & $1930-1940$ & $2000 / 14160$ \\
\hline Troyes* & $\begin{array}{l}\text { Concerts de l'école } \\
\text { nationale de musique** }\end{array}$ & & $1933-1940$ & $1000 / 3680$ \\
\hline Valenciennes & $\begin{array}{l}\text { Société des concerts du } \\
\text { conservatoire }\end{array}$ & 1913 & $1930-1940$ & $5000 / 56000$ \\
\hline Versailles* & Société des concerts** & & $1939-1940$ & 7000 \\
\hline
\end{tabular}




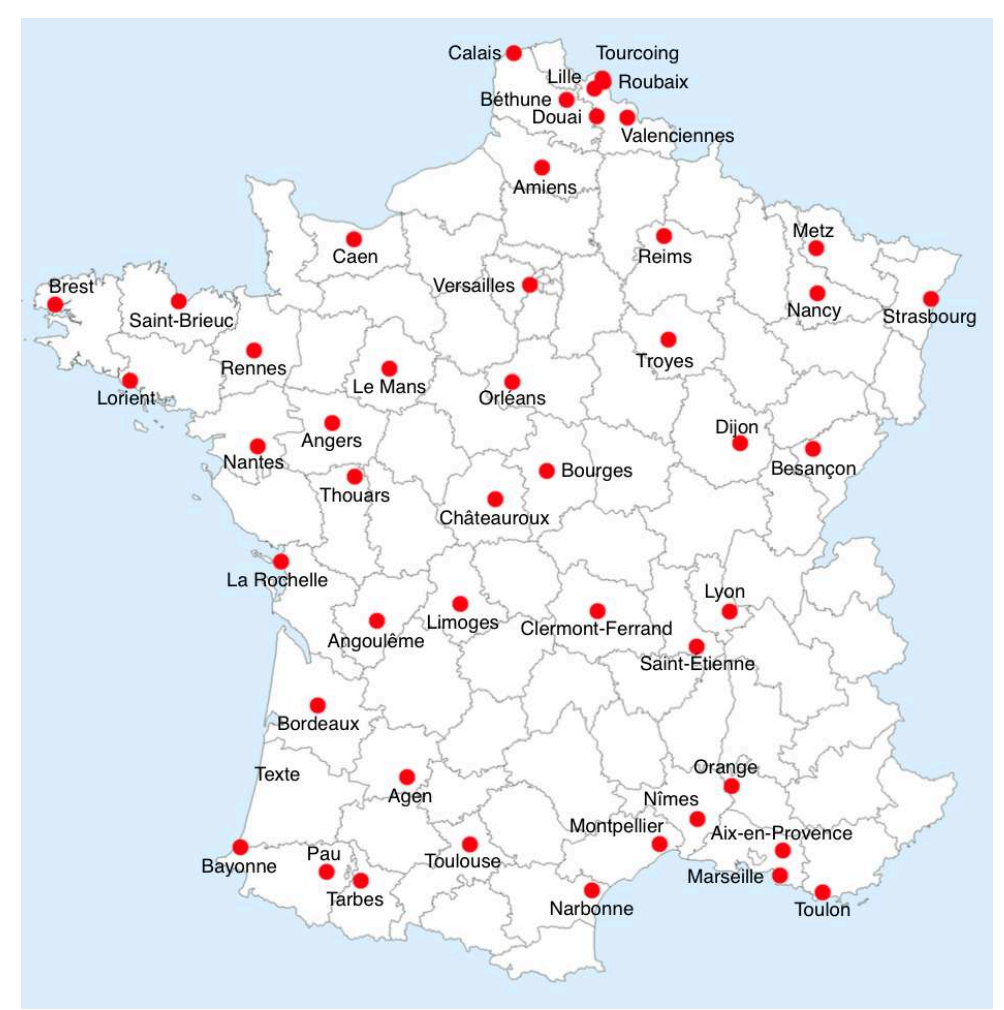

Sociétés de concerts symphoniques subventionnées par l'État entre 1930 et 1940

\section{Les années fastes de l'Occupation}

Les spécificités de la période de l'Occupation n'empêchent pas l'embryon de politique musicale de s'inscrire dans la continuité. Du reste, l'État français ne saurait être en désaccord avec les deux lignes de force qui caractérisent les années 1930 : la préférence nationale institutionnalisée et l'augmentation significative des subventions aux sociétés de concerts des régions. La capitale et avec elle une grande moitié - puis l'intégralité - du pays étant occupées, la décentralisation s'impose d'elle même à un gouvernement installé dans la ville de Vichy. Elle est d'autant plus assumée que les autorités nouvelles font du régionalisme l'un des axes de leur politique. Paradoxalement, c'est essentiellement depuis Paris qu'elle est conduite, du moins, dans le domaine de la musique.

L'occupation allemande et le régime de Vichy ne perturbent pas les activités de la Commission des concerts instaurée en 1932. Les inspecteurs de l'enseignement musical continuent d'y jouer un rôle déterminant malgré le non remplacement de l'inspecteur général depuis le décès d'Alfred Bruneau en 193499. C'est sur la base du rapport de l'inspecteur de l'enseignement musical André Bloch que s'opère la première répartition de l'Occupation au cours de la réunion du 3 décembre $1940^{100}$. Bloch détermine quatre catégories de sociétés sans que l'on puisse affirmer qu'il s'agit d'une innovation ${ }^{101}$ : les concerts des écoles nationales; les concerts indépendants des écoles nationales; les concerts de moindre importance; les propositions de refus de subvention. Ces derniers n'affectent que des sociétés sans activité. Un hommage particulier est rendu à « la ville héroïque de Tours où l'on fit, paraît-il, des répétitions sous le bombardement ${ }^{102}$ ! » 
50 Dans le domaine des concerts comme dans l'ensemble de l'activité musicale, le gouvernement de Vichy s'illustre par son interventionnisme et la création de comités d'organisation dont il conserve le contrôle ${ }^{103}$. C'est ainsi qu'il est institué par un arrêté du 11 mars 1941 auprès de la direction générale des Beaux-arts, un " comité consultatif en vue de la coordination des activités des associations de concerts symphoniques subventionnées (Gabriel Pierné104, Lamoureux, Pasdeloup, Société du Conservatoire [sic]) et de l'examen des questions intéressant l'ensemble de ces associations ${ }^{105}$." Présidé par le directeur général des Beaux-arts, ce comité consultatif a pour viceprésident le directeur du Conservatoire et réunit le chef du service de l'enseignement, des travaux d'art et des spectacles, l'administrateur de la Réunion des théâtres lyriques nationaux, les présidents-chefs d'orchestre des quatre associations symphoniques concernés, le président de la Sacem, le chef de bureau de la musique et des spectacles de la direction générale des Beaux-arts. On remarquera qu'une place de choix est réservée à Claude Delvincourt, le directeur du Conservatoire nouvellement nommé ${ }^{106}$ et surtout que le corps des inspecteurs de l'enseignement musical n'est pas représenté dans ce comité dont le champ d'intervention est réduit aux sociétés institutionnalisées. Il aura rapidement à se prononcer sur les projets de refonte du cahier des charges associée à une augmentation conséquente des subventions ${ }^{107}$.

51 Le comité consultatif ne semble pas porter atteinte aux activités de la Commission des concerts dont la composition évolue afin de tenir compte du renouvellement de l'organisation de la musique opéré par Vichy. Le procès verbal de la séance du 30 mars 1943 en témoigne ${ }^{108}$. Au coté de Louis Hautecœur, directeur général des Beauxarts, apparaissent le directeur du Conservatoire, Claude Delvincourt, le président du Comité professionnel des auteurs dramatiques, compositeurs et éditeurs de musique instauré par la loi du 30 novembre $1941^{109}$, Henri Rabaud, le président du Comité d'organisation professionnelle de la musique instauré par le décret du 24 mars $1942^{110}$, Alfred Cortot, le secrétaire général du Comité d'organisation des entreprises de spectacle instauré par un décret du 7 juillet $1941^{111}$, M. Reynaud, le directeur de l'Opéra, Marcel Samuel-Rousseau, et un inspecteur de l'enseignement musical, Joseph Szyfer. Les membres présents à cette séance du 30 mars 1943 portent leur attention, eux aussi, sur la révision du cahier des charges des sociétés de concerts institutionnalisées.

52 L'intérêt relatif porté par la Commission des concerts à ce qui est pourtant sa raison d'être, la répartition des crédits destinés aux sociétés de concerts des régions, ne doit pas masquer la hausse réelle des subventions à partir de 1942. Plus que d'une augmentation, néanmoins, il s'agit de la réaffectation de crédits initialement destinés au Commissariat à la lutte contre le chômage ${ }^{112}$. Il n'empêche que les sociétés de concerts bénéficient d'une manne inédite d'autant plus qu'elles sont moins nombreuses à se la partager. Après le pic de 1939 et deux années de baisse, 1942 et 1943 constituent une brève période d'euphorie, rapidement démentie par la diminution de 1944. Les crédits de 1939 sont multipliés par trois en 1943 même si, en francs constants, cette hausse est limitée à $67 \%$. Sur la même période, les sociétés reçoivent, en moyenne, des subventions quatre fois supérieures.

\begin{tabular}{|l|l|l|}
\hline Année & Nombre de sociétés subventionnées & Montant global (en francs) \\
\hline 1939 & 43 & 566100 \\
\hline
\end{tabular}




\begin{tabular}{|l|l|l|}
\hline 1940 & 36 & 490000 \\
\hline 1941 & 28 & 448800 \\
\hline 1942 & 32 & 1036250 \\
\hline 1943 & 33 & 1683000 \\
\hline 1944 & 30 & 811000 \\
\hline
\end{tabular}

Nombre de sociétés de concerts subventionnées et montant global des crédits répartis entre 1939 et 1944

53 La nouvelle organisation de la France, découpée en zones libre, occupée ou annexée qui sont amenées à évoluer sur l'ensemble de la période, ne modifie pas fondamentalement la géographie musicale du pays. Le cas de Metz constitue une exception : incluse dans les départements annexés par le Reich, elle ne peut plus recevoir de subvention pour sa société de concerts. Pour le reste, le subventionnement de l'État français ne tient pas compte des zones: 10 sociétés sont en zone libre, 17 en zone occupée, 5 dans les territoires rattachés au commandement militaire allemand à Bruxelles, 2 dans la zone d'occupation italienne, une dans la zone interdite ${ }^{113}$. La réduction du nombre des sociétés résulte des difficultés de la période empêchant une activité normale de la vie musicale. Ce sont essentiellement des petites sociétés qui sont concernées à l'image de la Société des concerts de l'école nationale de musique d'Aix-en-Provence, de la Société des concerts symphoniques de Besançon ou de l'Orchestre de l'école nationale de musique de Calais.

La réduction du nombre de sociétés subventionnées et la hausse des crédits profitent d'abord aux sociétés les plus importantes. Entre 1939 et 1943, la subvention de la Société des concerts du conservatoire de Toulouse est multipliée par cinq, celle de la Société des concerts populaires d'Angers et celles des Sociétés des concerts du conservatoire de Bordeaux, Nancy, Orléans et Rennes par quatre. Le double mouvement de réduction du nombre de sociétés et d'augmentation des crédits dessine une carte de France sur laquelle apparaît plus nettement que jamais une dizaine de villes dont une part importante est à la tête du mouvement symphonique français depuis des décennies. Le montant des subventions distribuées en 1943 permet d'en dresser un palmarès qui ne tient compte que de cet aspect quantitatif :

1/ Société des concerts du conservatoire de Toulouse (290000 F);

2-3/ Société des concerts populaires d'Angers et Société des concerts du conservatoire de Nancy (200 000 F);

4/ Sociétés des concerts du conservatoire de Bordeaux (200 $000 \mathrm{~F})$;

5/ Association philharmonique de Lyon (90 000 F) ;

6/ Association des concerts du conservatoire de Saint-Étienne (85 $000 \mathrm{~F})$;

7-8/ Association artistique des concerts classiques de Marseille et Société des concerts du conservatoire de Rennes (80 000 F);

9-11/ Association symphonique des concerts du conservatoire de Nantes, Association symphonique des concerts du conservatoire de Roubaix, Société des concerts du conservatoire de Valenciennes (65000 F). 
55 À l'évidence, les conditions particulières de l'Occupation font sortir de l'approximation, pour un temps du moins, l'embryon de politique musicale de l'État.

\begin{tabular}{|c|c|c|c|c|}
\hline Ville & Nom de la société & $\begin{array}{l}\text { Date de la } \\
\text { fondation }\end{array}$ & $\begin{array}{l}\text { Dates extrêmes du } \\
\text { subventionnement } \\
\text { pendant l'Occupation }\end{array}$ & $\begin{array}{l}\text { Montant minimal } \\
\text { et maximal de la } \\
\text { subvention (en } \\
\text { francs) }\end{array}$ \\
\hline Angers & $\begin{array}{l}\text { Société des concerts } \\
\text { populaires }\end{array}$ & 1877 & $1941-1944$ & $68000 / 200000$ \\
\hline Avignon* & $\begin{array}{l}\text { Société des } \\
\text { de l'école de } \\
\text { musique }\end{array}$ & & $1941-1944$ & $3000 / 5000$ \\
\hline Bordeaux & $\begin{array}{l}\text { Société des concerts } \\
\text { du conservatoire }\end{array}$ & & 1941-1944 & $35000 / 60000$ \\
\hline Bourges & $\begin{array}{l}\text { Association des } \\
\text { concerts de l'école } \\
\text { nationale de musique }\end{array}$ & 1927 & $1941-1943$ & $1000 / 2000$ \\
\hline Caen & $\begin{array}{l}\text { Concerts populaires } \\
\text { de l'école nationale } \\
\text { de musique }\end{array}$ & & 1941-1942 & $1250 / 2500$ \\
\hline Chambéry* & $\begin{array}{l}\text { Société des concerts } \\
\text { du conservatoire** }\end{array}$ & & $1942-1944$ & $2000 / 10000$ \\
\hline Châteauroux & Cercle symphonique & & $1942-1943$ & $5000 / 7000$ \\
\hline $\begin{array}{l}\text { Clermont- } \\
\text { Ferrand }\end{array}$ & $\begin{array}{lr}\text { Association } & \text { des } \\
\text { concerts } & d u \\
\text { conservatoire } & \end{array}$ & & 1941-1944 & $1000 / 15000$ \\
\hline Dijon & $\begin{array}{l}\text { Société des concerts } \\
\text { du conservatoire }\end{array}$ & & $1941-1944$ & $3000 / 7000$ \\
\hline Douai & $\begin{array}{l}\text { Société des concerts } \\
\text { symphoniques du } \\
\text { conservatoire }\end{array}$ & & $1943-1944$ & 2000 \\
\hline $\begin{array}{l}\text { Enghien-les- } \\
\text { Bains* }\end{array}$ & $\begin{array}{lr}\text { Orchestre } & \text { de } \\
\text { chambre } & \text { Daniel } \\
\text { Stirn } & \end{array}$ & & 1944 & 5000 \\
\hline Le Mans & $\begin{array}{l}\text { Société des concerts } \\
\text { du conservatoire }\end{array}$ & & $1941-1943$ & $5950 / 16000$ \\
\hline Lille & $\begin{array}{l}\text { Société des concerts } \\
\text { populaires }\end{array}$ & 1877 & $1941-1944$ & $12000 / 30000$ \\
\hline
\end{tabular}




\begin{tabular}{|c|c|c|c|c|}
\hline Lorient & $\begin{array}{l}\text { Société des concerts } \\
\text { de l'école de musique }\end{array}$ & & $1941-1944$ & $3000 / 8000$ \\
\hline Lyon & $\begin{array}{l}\text { Association } \\
\text { philharmonique }\end{array}$ & 1905 & $1941-1944$ & $35000 / 90000$ \\
\hline Marseille & $\begin{array}{lr}\text { Association } & \text { artistique } \\
\text { des } & \text { concerts } \\
\text { classiques } & \end{array}$ & 1886 & $1941-1944$ & $7500 / 80000$ \\
\hline Nancy & $\begin{array}{ll}\text { Concerts } & d u \\
\text { conservatoire } & \end{array}$ & 1884 & 1941-1944 & $50000 / 200000$ \\
\hline & $\begin{array}{l}\text { Schola cantorum de } \\
\text { Nantes** }\end{array}$ & 1913 & $1942-1944$ & $27500 / 45000$ \\
\hline Nantes & $\begin{array}{lr}\text { Association } & \\
\text { symphonique } & \text { des } \\
\text { concerts } & \text { du } \\
\text { conservatoire } & \end{array}$ & 1938 & 1941-1944 & $3500 / 65000$ \\
\hline Nîmes & $\begin{array}{l}\text { Société des concerts } \\
\text { du conservatoire }\end{array}$ & & 1942 & 10000 \\
\hline Orléans & $\begin{array}{l}\text { Société des concerts } \\
\text { du conservatoire }\end{array}$ & 1921 & $1941-1944$ & $12000 / 40000$ \\
\hline Poitiers* & $\begin{array}{l}\text { École municipale de } \\
\text { musique }^{* *}\end{array}$ & & $1942-1944$ & $10000 / 18000$ \\
\hline Reims & $\begin{array}{l}\text { Société des concerts } \\
\text { de l'école nationale } \\
\text { de musique }\end{array}$ & & $1941-1944$ & $7000 / 40000$ \\
\hline Rennes & $\begin{array}{l}\text { Société des concerts } \\
\text { du conservatoire }\end{array}$ & 1897 & 1941-1944 & $21000 / 80000$ \\
\hline Roanne* & $\begin{array}{l}\text { Société } \\
\text { philharmonique** }\end{array}$ & & $1942-1944$ & $2000 / 5000$ \\
\hline Roubaix & $\begin{array}{ll}\text { Association } & \\
\text { symphonique de } & \text { d'école nationale de } \\
\text { musique } & \end{array}$ & 1889 & 1941-1944 & $12000 / 65000$ \\
\hline Saint-Brieuc & $\begin{array}{l}\text { Société } \\
\text { philharmonique }\end{array}$ & & 1941-1944 & $750 / 6000$ \\
\hline Saint-Étienne & $\begin{array}{lr}\text { Association } & \text { des } \\
\text { concerts } & d u \\
\text { conservatoire } & \end{array}$ & 1930 & $1941-1944$ & $40000 / 85000$ \\
\hline
\end{tabular}




\begin{tabular}{|c|c|c|c|c|}
\hline Tarbes & $\begin{array}{l}\text { Société } \\
\text { philharmonique }\end{array}$ & & $1941-1944$ & $5000 / 14000$ \\
\hline Toulon & $\begin{array}{l}\text { Société des concerts } \\
\text { du conservatoire }\end{array}$ & 1906 & $1941-1943$ & $5000 / 10000$ \\
\hline Toulouse & $\begin{array}{l}\text { Société des concerts } \\
\text { du conservatoire }\end{array}$ & 1902 & $1941-1944$ & $35000 / 290000$ \\
\hline Tourcoing & $\begin{array}{l}\text { Société des concerts } \\
\text { du conservatoire }\end{array}$ & & 1941-1944 & $10000 / 20000$ \\
\hline Tours* & $\begin{array}{l}\text { Société des concerts } \\
\text { du conservatoire** }\end{array}$ & & 1941-1944 & $6000 / 22000$ \\
\hline Troyes & $\begin{array}{l}\text { Concerts de l'école } \\
\text { nationale de musique }\end{array}$ & & 1941-1944 & $2100 / 15000$ \\
\hline Valenciennes & $\begin{array}{l}\text { Société des concerts } \\
\text { du conservatoire }\end{array}$ & 1913 & 1941-1944 & $35000 / 65000$ \\
\hline Versailles & Société des concerts & & 1941-1942 & $1000 / 6500$ \\
\hline
\end{tabular}

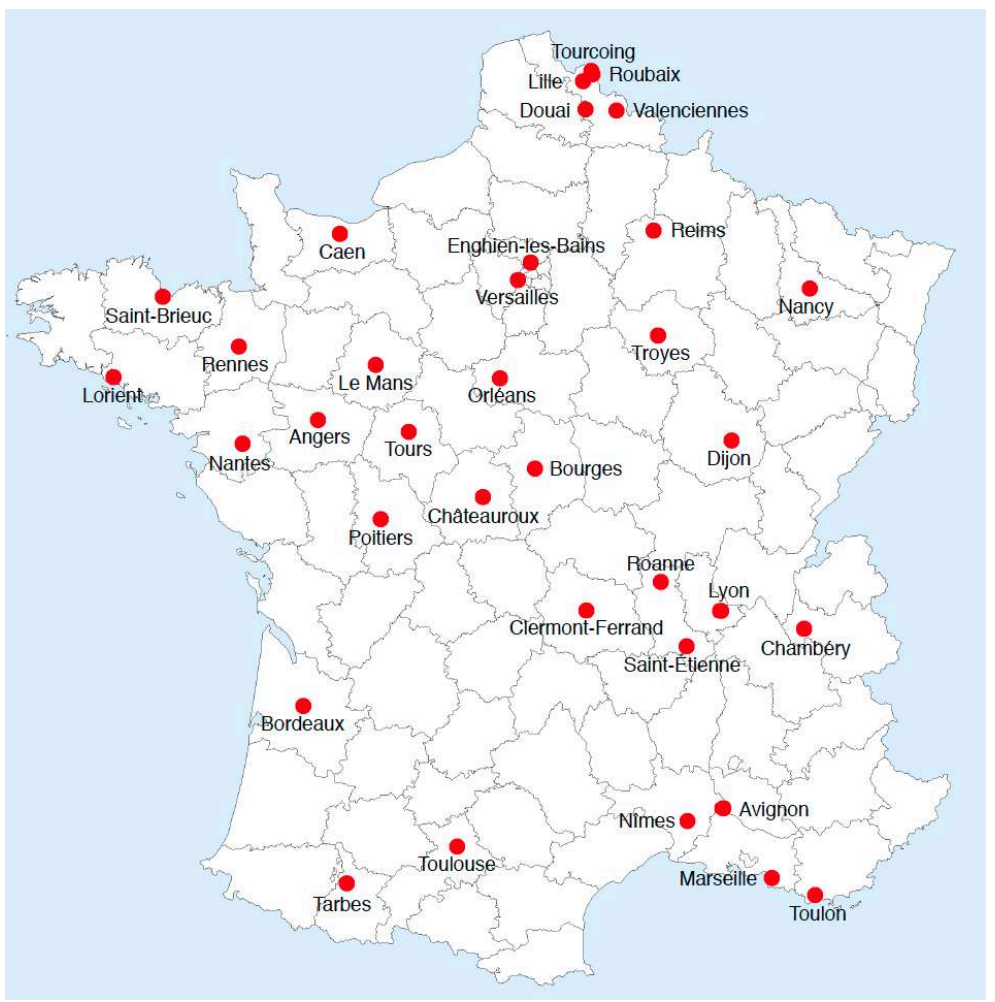

Sociétés de concerts symphoniques subventionnées par l'État entre 1941 et $1944^{114}$ 


\section{Une commission hégémonique (1944-1966)}

56 concerts la possibilité d'élargir son périmètre d'intervention et son influence sur la vie musicale dans une perspective nationaliste plus que jamais affirmée avec détermination. concerts fait l'objet d'une dizaine d'arrêtés ministériels définissant ses compétences et la composition de ses membres. Le premier d'entre eux est celui du 10 juillet 1945 instaurant une «commission consultative chargée d'examiner les problèmes intéressant les concerts symphoniques" sans mention ni abrogation des textes précédents. La même absence de référence aux arrêtés antérieurs vaut pour celui du 9 mai 1946 instituant une «Commission consultative chargée d'examiner les demandes de subvention présentées par les sociétés de concerts de Paris et des départements. » Cette instance consultative fusionne, par un arrêté du 9 mars 1955 avec la " commission consultative chargée de délibérer sur l'emploi du crédit affecté aux commandes à des compositeurs de musique et toutes questions intéressant l'encouragement de la composition musicale instaurée par arrêté du 12 août 1947. »Cette évolution témoigne de la montée en puissance de la Commission des concerts. Les autres arrêtés qui lui sont consacrés vont dans le même sens. Ils sont relatifs à la liste des membres qui ne cesse de s'allonger en accueillant un nombre de personnalités extérieures de plus en plus élevé. Alors qu'elles étaient quatre en 1941, elles sont sept sur l'arrêté du 21 avril 1961.

tialement destinée à émettre des avis sur la répartition des subventions aux sociétés de concerts, la Commission des concerts élargit progressivement son champ d'intervention. Sollicitée par l'administration des Beaux-arts, elle porte des avis sur divers sujets. Le 22 novembre 1947, Jeanne Laurent, qui préside la séance, adresse trois questions à la Commission. Elle lui demande s'il faut autoriser des artistes de l'Opéra à participer à un enregistrement du Faust de Gounod en Angleterre pour le compte de la firme La Voix de son maître. Elle l'interroge sur l'opportunité de reprendre à l'Opéra et à l'Opéra-Comique les œuvres de Richard Strauss. Sur ce point, la réponse est positive : «Compte tenu du talent de ce compositeur, des sentiments francophiles et antinazis dont il n'a cessé de faire preuve avant et pendant la guerre, la Commission émet à l'unanimité un avis très favorable à la reprise des œuvres de Richard Strauss. » Enfin, «la Commission est consultée sur l'incorporation des femmes dans les orchestres symphoniques. M. Delvincourt déclare que la nécessité d'une unité de présentation s'y oppose. La Commission adopte ce point de vue et estime d'une façon générale que la participation des femmes n'est pas souhaitable ${ }^{115}$. " Le 31 mai 1948, la commission est sollicitée pour donner son avis sur le choix de l'ouvrage lyrique qui sera donné dans le cadre de la prochaine session de l'Organisation des nations unies prévue à Paris ${ }^{116}$.

Parmi les sujets abordés par la Commission des concerts au cours de ses séances des premières années de l'immédiat après-guerre, figure celui de l'épuration. Des encouragements à des manifestations musicales sont refusés ou soumis à des conditions au motif qu'elles accueillent des interprètes dont le comportement sous l'Occupation est jugé critiquable. C'est le cas de Marius-François Gaillard: la Commission estime le 9 mai 1947 qu'il «serait inopportun de subventionner des concerts dirigés par M. Gaillard étant donné que la participation de ce chef d'orchestre risque d'entraîner 
des protestations analogues à celles qui ont eu lieu au cours du récital de M. Cortot ${ }^{117}$. » La subvention de 100000 francs sera versée si Gaillard est exclu. Le chef d'orchestre sollicite lui-même l'État pour son Association des concerts Marius-François Gaillard mais se voit opposer une fin de non recevoir le 11 décembre 1947 pour des raisons identiques. Pour sa part, le 10 décembre 1948, le tout nouveau festival de Besançon, même s'il obtient finalement gain de cause, se voit reprocher d'avoir invité la pianiste Marcelle Meyer, «dont l'attitude pendant la défaite et l'Occupation n'a pas été irréprochable ${ }^{118}$.»

Plus que jamais, et plus encore que sous l'Occupation dont elle tente de solder les comptes, la Commission des concerts fait du nationalisme musical une priorité. Le nombre des références à la primauté de la défense de la musique française dans les comptes rendus de ses séances atteint un niveau inconnu sous l'Occupation. La place de la musique française dans les programmes et celle des chefs d'orchestres nationaux sur les estrades influencent ou conditionnent les choix de la Commission. C'est ainsi que le 11 décembre 1947 elle affirme que l'aide financière de l'État à la Société des concerts du conservatoire de Paris «se situe uniquement sur le plan artistique et qu'elle est destinée à favoriser le développement du patrimoine musical français. » Les incessantes révisions du cahier des charges des sociétés parisiennes sont dictées par cet impératif. Malgré l'absence de toute convention entre l'État et les orchestres départementaux, les orientations nationalistes de la Commission ne sont pas sans conséquence sur l'ensemble du territoire. Le 12 avril 1947, à propos d'un festival Bach à Strasbourg, Roger Désormière « fait état de témoignages qui lui ont été rapportés sur la trop grande part faite en Alsace à la musique allemande.» Le 13 mai 1949, à propos du festival d'Aix-en-Provence, le directeur de l'Opéra de Paris «tient à appeler l'attention de la Commission sur le fait que les seules représentations lyriques prévues au programme d'Aix-en-Provence sont celles de «Don Juan » et qu'elles seront jouées par des artistes étrangers; or, la musique française, devrait occuper une place prépondérante dans ces festivals. " Le 28 juin 1950, Amable Massis, inspecteur général de l'enseignement musical, fait remarquer qu'aucune part n'a été faite à la musique française dans les programmes du premier semestre de l'Association des concerts symphoniques de Toulouse, et que, «à son avis une pénalisation s'impose, à titre d'avertissement. » Le même jour, des sanctions pécuniaires sont effectivement prises à l'encontre du festival de Besançon dont la part de la musique française dans les programmes «serait presque nulle.» Le 3 juillet 1951, une amende, sous la forme de la baisse de la subvention annoncée, est infligée au festival d'Aix-en-Provence. Les festivals sont particulièrement ciblés. Il leur est reproché, le 27 février 1952, de ne pas servir « la musique française puisque aucune œuvre de compositeurs français n'est inscrite à leurs programmes.» Ces critères se heurtent néanmoins aux attentes du public qui, selon Jeanne Laurent, «ne viendrait pas aux festivals si ceux-ci ne comportaient uniquement que des œuvres de musique française ${ }^{119}$.»

61 La distance temporelle avec l'Occupation ne s'accompagne pas d'une remise en cause de cet objectif. On en retrouve la trace en 1957, date à laquelle l'Orchestre philharmonique de Bordeaux voit sa subvention amputée malgré l'intervention du charismatique maire de la ville et ministre d'État, Jacques Chaban-Delmas. L'insuffisance de la musique française et le nombre trop élevé de chefs d'orchestre étrangers sont mis en cause ${ }^{120}$. En 1965, au cours de la séance du 15 juin, la commission approuve le barème imposé aux sociétés parisiennes. Il « tient compte des efforts faits en faveur de la musique française et contemporaine et des chefs d'orchestre et interprètes français ${ }^{121}$.» La qualité passe 
après la défense de la musique et des musiciens français : Henri Sauguet regrette que les Concerts Lamoureux soient défavorisés mais il se heurte à la réponse d'Emmanuel Bondeville qui «pense que la musique, les auteurs et les musiciens français doivent être défendus avant tout. » Cette stratégie atteint néanmoins son paroxysme et son terme puisque, au cours de la même séance, Émile Biasini, le directeur du théâtre, de la musique et de l'action culturelle au sein du ministère des Affaires culturelles, donne aux représentants des grandes associations présents à la réunion " l'assurance que dès l'année prochaine, un système nouveau de répartition des subventions sera mis en application, selon le vœu de la Commission nationale pour l'étude des problèmes de la musique $^{122}$."

62 La Commission des concerts ne se contente pas d'encourager avec beaucoup d'insistance la défense de la musique et des musiciens français, elle veut imposer un répertoire aux formations symphoniques. Cette pratique ne connaît pas d'équivalent dans l'histoire du concert en France, pas même sous l'occupation. C'est ainsi que le 28 octobre 1947, la commission dresse une « liste d'œuvres à proposer aux associations symphoniques $^{123}$. "Une centaine de compositeurs français et environ le double d'œuvres sont mentionnés. La tentation de définir un corpus des œuvres contemporaines apparait à d'autres reprises, notamment, le 21 septembre 1948. Alors qu'un membre de la commission, le musicographe René Dumesnil propose de fournir aux associations la liste des œuvres qu'elles devraient jouer, les représentants de l'administration se montrent réticents. Jacques Jaujard «craint qu'il soit difficile d'imposer un système basé sur une trop grande contrainte, » tandis que Jeanne Laurent propose «de donner une subvention spéciale pour l'exécution de certaines œuvres déterminées ainsi que cela se pratique pour le théâtre ${ }^{124}$.» Des œuvres défendues par des sociétés de concerts font l'objet d'appréciations négatives. Au cours de la séance du 15 juin 1950, « MM. Aubert et Raugel insistent sur la médiocrité d'un ouvrage présenté en première audition, le Poème biblique de Bernard Loth ${ }^{125}$. "Le caractère religieux de l'œuvre n'est peut-être pas sans lien avec ce type de condamnation dont le degré suivant est celui de la censure, effleurée le 29 novembre 1951. À cette date, Jeanne Laurent «fait savoir que la Messe du révérend père Martin doit être donnée par la Société des concerts du Conservatoire. Y a-t-il lieu d'interdire cette œuvre? La Commission pense qu'elle ne peut établir une censure musicale et doit laisser la Société des concerts entièrement libre de jouer cette cuvre $^{126}$." Ce sera chose faite le 9 mars 1952.

63 Tout en élargissant son domaine d'intervention et en affirmant une doctrine nationaliste, la Commission continue d'apporter à l'État un avis sur la répartition des crédits alloués aux sociétés de concerts françaises. Sur cette question, le rôle des inspecteurs de l'enseignement musical reste prédominant tout au long de la période. Après le décès de l'inspecteur général Joseph Szyfer en 1947, son remplaçant, le compositeur Amable Massis se voit confier la mission d'organiser les évaluations des sociétés de concerts et d'en présenter une synthèse devant la commission. Sous son impulsion, des tentatives de classement et de catégorisation des orchestres sont réalisées pour faire face au nombre élevé des demandes. Le 11 décembre 1950, Massis propose un classement en six catégories basées sur l'importance de l'orchestre, le nombre des concerts avec ou sans chœur ${ }^{127}$. Ces expérimentations semblent ne pas connaître une grande fortune d'autant plus qu'elles se heurtent aux critères propres de la Commission. Il n'empêche que la dispersion des subventions fait l'objet de critiques récurrentes mais elle est présentée comme une nécessité par l'administration. Celle-ci 
redoute le pouvoir de nuisance des parlementaires des départements sur les dotations des Beaux-arts et veille à proposer une répartition qui soit aussi électoraliste des subventions aux formations symphoniques. Leur niveau restant insuffisant, elles demeurent néanmoins avant tout symboliques.

Même si, dans l'état actuel de nos recherches, les chiffres dont nous disposons sont parcellaires, on peut constater, du moins jusqu'à la fin des années 1950, une augmentation du nombre des sociétés de concerts subventionnées ${ }^{128}$. Après avoir été 43 en 1939, 33 en 1943 et 30 en 1944, elles sont 51 en 1958. Du reste, 1958 peut servir d'année de référence et être comparée à 1943, année faste de l'Occupation. Entre ces deux années, le montant global des subventions, en euros constants, est divisé par trois ${ }^{129}$. Si le nombre des sociétés subventionnées passe bien de 33 à 51, l'augmentation ne reflète qu'imparfaitement l'évolution, puisque plus de la moitié des sociétés subventionnées en 1951 n'existaient pas ou n'étaient pas aidées en 1943. C'est le cas des sociétés de l'est de la France : à elles seules, les villes de Metz, Mulhouse et Strasbourg perçoivent 1300000 francs pour ce qui pourrait être qualifié de second rattrapage après cette nouvelle période d'annexion. Pour leur part, les villes traditionnellement parmi les mieux dotées, celles d'Angers, Bordeaux, Lyon, Marseille et Nancy, conservent ce statut dont seule la ville de Toulouse est exclue. Elles sont rejointes par une cohorte de villes moyennes qui se répartissent sur l'ensemble du territoire.

\begin{tabular}{|c|c|c|c|}
\hline Ville & Nom de la société & $\begin{array}{l}\text { Date de la } \\
\text { fondation }\end{array}$ & $\begin{array}{l}\text { Subvention (en } \\
\text { francs) }\end{array}$ \\
\hline Amiens & Association des concerts du conservatoire & & 70000 \\
\hline Angers & Société des concerts populaires & $1877-$ & 300000 \\
\hline Arras & $\begin{array}{l}\text { Société des concerts de l'école nationale de } \\
\text { musique }\end{array}$ & $1952-$ & 50000 \\
\hline Avignon & Société des concerts de l'école de musique & & 60000 \\
\hline Besançon & Société des concerts symphoniques & $1907-$ & 150000 \\
\hline Bordeaux & Orchestre municipal & & 200000 \\
\hline Bourges & $\begin{array}{l}\text { Association des concerts de l'école nationale } \\
\text { de musique }\end{array}$ & $1927-$ & 100000 \\
\hline Brest & $\begin{array}{l}\text { Association des concerts symphoniques } \\
\text { brestois }\end{array}$ & $1947-$ & 90000 \\
\hline Caen & Orchestre municipal & & 150000 \\
\hline Cambrai & Société des concerts classiques & $1948-$ & 70000 \\
\hline $\begin{array}{l}\text { Clermont- } \\
\text { Ferrand }\end{array}$ & Association des concerts du conservatoire & & 160000 \\
\hline & Société des concerts du conservatoire & & 300000 \\
\hline
\end{tabular}




\begin{tabular}{|c|c|c|c|}
\hline & Schola cantorum & & 20000 \\
\hline Douai & $\begin{array}{l}\text { Société des concerts symphoniques du } \\
\text { conservatoire }\end{array}$ & 1925 / 1931- & 90000 \\
\hline Grenoble & Concerts de l'école nationale de musique & 1953- & 200000 \\
\hline La Rochelle & Société philharmonique & $1815-$ & 15000 \\
\hline Laval & Société philharmonique & $1839-$ & 15000 \\
\hline Le Mans & Société des concerts du conservatoire & 1928 / 1931- & 90000 \\
\hline Lille & $\begin{array}{l}\text { Société des concerts populaires / Société } \\
\text { des concerts du conservatoire }\end{array}$ & 1877- & 140000 \\
\hline Lorient & Société des concerts populaires & & 40000 \\
\hline Lyon & Association philharmonique (1938) & $1905-$ & 430000 \\
\hline Macon & Concerts de l'école municipale & & 30000 \\
\hline Marseille & $\begin{array}{l}\text { Association artistique des concerts } \\
\text { classiques }\end{array}$ & 1886- & 350000 \\
\hline Metz & Association des concerts du conservatoire & $1946-$ & 250000 \\
\hline Montpellier & Orchestre municipal & & 40000 \\
\hline Moulins & Société des amis de la musique & & 15000 \\
\hline Mulhouse & Orchestre philharmonique & & 250000 \\
\hline Nancy & Société des concerts du conservatoire & $1884-$ & 250000 \\
\hline \multirow{2}{*}{ Nantes } & Schola cantorum de Nantes & 1913- & 100000 \\
\hline & $\begin{array}{l}\text { Association symphonique des concerts du } \\
\text { conservatoire }\end{array}$ & 1938-1969 & 100000 \\
\hline Nice & Orchestre municipal & 1946- & 140000 \\
\hline Nîmes & Société des concerts du conservatoire & & 80000 \\
\hline Orléans & Société des concerts du conservatoire & $1921-$ & 70000 \\
\hline Pau & Société des concerts du conservatoire & & 30000 \\
\hline Perpignan & Société des concerts du conservatoire & & 45000 \\
\hline Poitiers & École municipale de musique & & 30000 \\
\hline Reims & Orchestre municipal & & 120000 \\
\hline
\end{tabular}




\begin{tabular}{|c|c|c|c|}
\hline Rochefort & Société philharmonique & & 25000 \\
\hline Romans & Société des concerts & $1948-$ & 30000 \\
\hline Roubaix & $\begin{array}{l}\text { Association symphonique... / Société des } \\
\text { concerts du conservatoire }\end{array}$ & 1889- / 1951- & 90000 \\
\hline Rouen & Concerts du conservatoire & $1946-$ & 100000 \\
\hline Saint-Brieuc & Société philharmonique & & 50000 \\
\hline Saint-Étienne & Association des concerts du conservatoire & $1930-$ & 100000 \\
\hline \multirow{3}{*}{ Strasbourg } & Orchestre municipal & $1875-$ & 400000 \\
\hline & Concerts de l'église Saint-Guillaume & & 200000 \\
\hline & Chorale de la cathédrale & & 200000 \\
\hline Thouars & Société des concerts & $1921-$ & 10000 \\
\hline Toulon & Société des concerts du conservatoire & $1906-$ & 60000 \\
\hline Toulouse & Orchestre de chambre & & 175000 \\
\hline Troyes & Concerts de l'école nationale de musique & & 100000 \\
\hline Valenciennes & Société des concerts du conservatoire & 1913- & 130000 \\
\hline
\end{tabular}

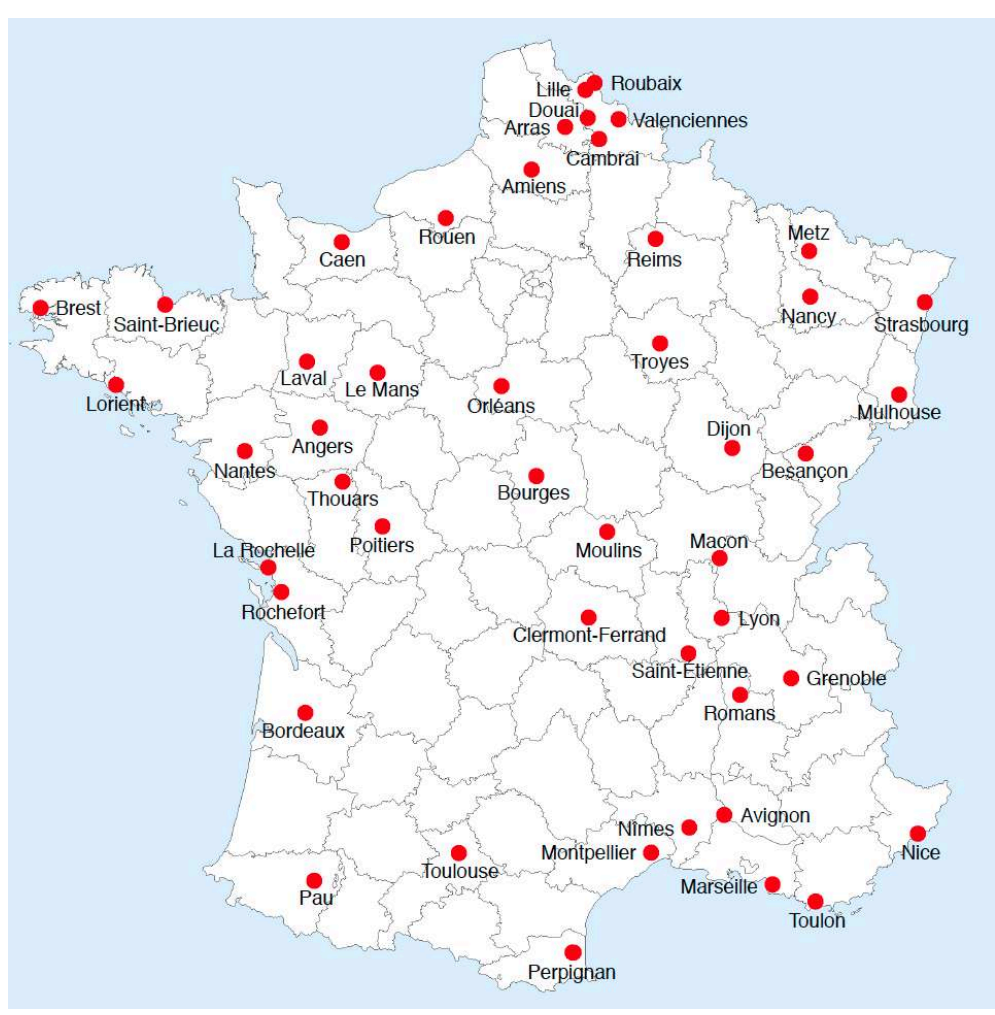

Sociétés de concerts symphoniques subventionnées par l'État en 1958 
65

Cette liste de 51 sociétés comporte six " orchestres municipaux » dans les villes de Bordeaux, Caen, Montpellier, Nice, Reims et Strasbourg. Cette dénomination n'apparaît qu'au lendemain de la Seconde Guerre mondiale et semble désigner une structure spécifique pour laquelle une ligne de crédit est ajoutée dans le budget de l'État. La subvention ne leur est pas octroyée directement mais par l'entremise des «villes qui entretiennent à leur frais un orchestre municipal ${ }^{130}$. » Rien ne permet de dire que cette appellation est associée à un statut spécifique et à un engagement financier précis - en 1958, les subventions varient entre 40000 francs à 400000 francs. On constate, du reste, que la liste des bénéficiaires est en constante évolution. En 1947, elle comprenait Bordeaux, Lille, Nancy, Nice, Mulhouse et Strasbourg. En 1951, « la Société des concerts de Rouen devient un orchestre municipal étant donné son importance ${ }^{131}$.» Le 15 juin 1965, Émile Biasini propose d'étendre la liste des orchestres municipaux en y ajoutant «certains orchestres assurant la vie musicale en Province et remplissant sensiblement le même rôle. " Aux sept actuels orchestres municipaux, à Bordeaux, Metz, Mulhouse, Nancy, Nice, Rouen et Strasbourg, seraient ajoutées les formations symphoniques d'Angers, Dijon, Grenoble, Lyon et Marseille ${ }^{132}$. Pour le moins, l'apparition de ces orchestres municipaux est un signe supplémentaire d'une volonté de différenciation plus marquée entre les sociétés de concerts. D'une certaine manière, elle annonce la fin d'une politique de maillage du territoire française à laquelle celle des pôles régionaux va bientôt se substituer.

\section{La préparation du Plan Landowski}

66 La création de la Direction de la musique au sein du ministère des Affaires culturelles et la nomination de Marcel Landowski à sa tête mettent un terme au système dont la création de la Commission des concerts en 1932 pourrait être considérée comme l'inauguration. À l'heure de la radio et des enregistrements discographiques, face à la concurrence du cinéma international et de la télévision, l'entretien d'un nombre élevé d'orchestres et le saupoudrage des deniers publics n'apparaît plus comme la solution la plus adaptée. On leur préfère la rationalisation, la professionnalisation et le rayonnement. La transformation de la Société des concerts du Conservatoire en Orchestre de Paris dès 1967 est le symbole de cette évolution de la politique musicale de l'État que Landowski étendra à l'ensemble du territoire.

Ces orientations sont exposées au cours de la première réunion de la nouvelle Commission des concerts créée par un arrêté du 3 mars 1967 «instaurant une commission chargée de donner au ministre son avis sur toutes les questions que celui-ci lui soumet en matière de subventions aux diverses organismes musicaux ainsi que sur celles concernant l'emploi des crédits affectés à l'exécution, l'animation, l'initiation et l'édition musicales, et plus généralement sur toute question intéressant le développement de la vie musicale ${ }^{133}$." La rédaction de l'arrêté tient compte de l'élargissement des prérogatives de la Commission depuis la Libération. La séance du 14 mars 1967 permet au nouveau directeur de la Musique d'exposer «la nouvelle politique entreprise par M. le Ministre d'État en faveur de la Musique » :

Il s'agira dorénavant, en échange de subventions plus importantes, de promouvoir et de contrôler par le moyen de conventions précises signées avec l'État par les organismes musicaux subventionnés, une politique de création, de large action culturelle et de qualité d'interprétation devant permettre, sous le contrôle de l'État un épanouissement et un rayonnement nouveau de la Musique ${ }^{134}$. 
orientation vaut tout autant pour Paris que pour les régions où l'objectif est de constituer des orchestres régionaux de grande valeur avec deux principes: implantation locale et irradiation régionale. Deux villes sont proposées pour tester cette nouvelle politique : Lyon et Angers. Est-il besoin de rappeler qu'il s'agit de deux des principales villes françaises dans lesquelles un orchestre est actif sur une longue période et en dehors du théâtre tout en étant parmi les plus subventionnées par l'État? Le discours a fondamentalement changé: la langue de la nouvelle Commission a recours aux mot convention, contrôle, politique de création, action culturelle, rayonnement. C'en est fini de l'objectif unique de servir la musique, les compositeurs et les musiciens français !

Avant même la mise en place du Plan Landowski, la politique de subventionnement des sociétés de concerts se veut plus limitative. Pour 1968, trois groupes sont constitués : les orchestres municipaux de $1^{\text {re }}$ catégorie, les autres orchestres municipaux, les associations des régions ${ }^{135}$. Alors qu'ils étaient 51 en 1958, les orchestres subventionnés ne sont plus que 33 en 1969. Dans le même temps les crédits qui leur sont alloués sont en nette augmentation ${ }^{136}$. Par ailleurs, sur les tableaux récapitulant les subventions des orchestres, une colonne est réservée aux commentaires qualitatifs. Les seules sociétés subventionnées en 1969 qui ne l'étaient pas onze ans plus tôt sont l'Association des concerts du conservatoire d'Aix-en-Provence, la Société des concerts symphoniques de Dôle, la Société des concerts du conservatoire de Limoges, la Société des concerts de l'école nationale de musique de Reims, l'Association des concerts symphoniques de Bretagne (Rennes), l'Association des concerts du conservatoire de musique de Sarreguemines et la Société des concerts du conservatoire de Tours. Indépendamment de la diminution du nombre d'orchestres et de l'absence des futurs pôles régionaux, l'État encourage nettement certaines formations: l'Association des concerts symphoniques de Bretagne (12000 francs) ; la Société des concerts du conservatoire de Dijon, les Concerts de l'école nationale de musique de Grenoble, l'Orchestre philharmonique de Mulhouse (13000 francs); l'Association des concerts du conservatoire de Metz, la Société des concerts du conservatoire de Nancy (18 000 francs). Aucune des autres subventions ne dépasse 4000 francs.

\begin{tabular}{|l|l|l|l|}
\hline Ville & Nom de la société & $\begin{array}{l}\text { Date de la } \\
\text { fondation }\end{array}$ & $\begin{array}{l}\text { Subvention (en } \\
\text { francs) }\end{array}$ \\
\hline $\begin{array}{l}\text { Aix-en- } \\
\text { Provence }\end{array}$ & Association des concerts du conservatoire & $1960-$ & 2000 \\
\hline Amiens & Association des concerts du conservatoire & & 2000 \\
\hline Avignon & Société des concerts de l'école de musique & & 2500 \\
\hline Bayonne & Société des concerts du conservatoire & & 2000 \\
\hline Bordeaux & Orchestre municipal & 4000 \\
\hline Bourges & $\begin{array}{l}\text { Association des concerts de l'école } \\
\text { nationale de musique }\end{array}$ & $1927-$ & 2500 \\
\hline
\end{tabular}




\begin{tabular}{|c|c|c|c|}
\hline Brest & $\begin{array}{l}\text { Association des concerts symphoniques } \\
\text { brestois }\end{array}$ & 1947- & 2000 \\
\hline Caen & Orchestre municipal & & 4000 \\
\hline Dijon & Société des concerts du conservatoire & & 13000 \\
\hline Douai & $\begin{array}{l}\text { Société des concerts symphoniques du } \\
\text { conservatoire }\end{array}$ & 1925 / 1931- & 2500 \\
\hline Grenoble & Concerts de l'école nationale de musique & 1953- & 13000 \\
\hline La Rochelle & Société philharmonique & $1815-$ & 2500 \\
\hline Le Mans & Société des concerts du conservatoire & 1928 / 1931- & 2500 \\
\hline Limoges & Société des concerts du conservatoire & & 2000 \\
\hline Metz & Association des concerts du conservatoire & $1946-$ & 18000 \\
\hline Mulhouse & Orchestre philharmonique & & 13000 \\
\hline Nancy & $\begin{array}{l}\text { Concerts populaires / Société des concerts } \\
\text { du conservatoire }\end{array}$ & $1884-$ & 18000 \\
\hline Nantes & Schola cantorum de Nantes & 1913- & 1000 \\
\hline Nantes & $\begin{array}{l}\text { Association symphonique des concerts du } \\
\text { conservatoire }\end{array}$ & $1938-1969$ & 1500 \\
\hline Nice & Orchestre municipal & $1946-$ & 4000 \\
\hline Orléans & Société des concerts du conservatoire & $1921-$ & 1000 \\
\hline Pau & Société des concerts du conservatoire & & 1000 \\
\hline Poitiers & École municipale de musique & & 1000 \\
\hline Reims & $\begin{array}{l}\text { Société des concerts de l'école nationale de } \\
\text { musique }\end{array}$ & & 3000 \\
\hline Rennes & $\begin{array}{l}\text { Association des concerts symphoniques de } \\
\text { Bretagne }\end{array}$ & & 10000 \\
\hline Romans & Société des concerts & $1948-$ & 1000 \\
\hline Roubaix & $\begin{array}{l}\text { Association symphonique... / Société des } \\
\text { concerts du conservatoire }\end{array}$ & 1889- / 1951- & 2000 \\
\hline Saint-Étienne & Association des concerts du conservatoire & $1930-$ & 1000 \\
\hline Strasbourg & Orchestre municipal & $1875-$ & 4000 \\
\hline
\end{tabular}




\begin{tabular}{|l|l|l|l|}
\hline Tours & Société des concerts du conservatoire & & 4000 \\
\hline Troyes & Concerts de l'école nationale de musique & & 2000 \\
\hline Valenciennes & Société des concerts du conservatoire & $1913-$ & 2000 \\
\hline
\end{tabular}

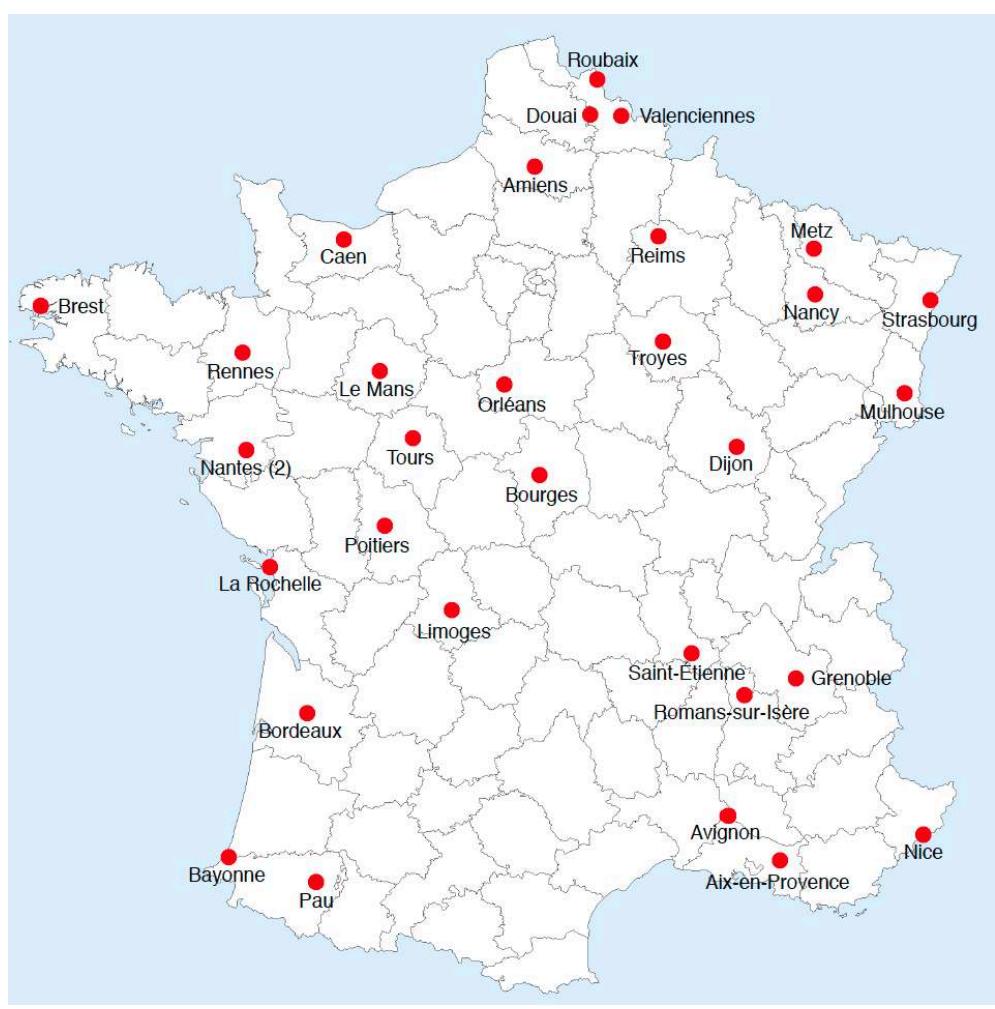

Sociétés de concerts symphoniques subventionnées par l'État en 1969

Plus de cent ans après la fondation des Concerts Pasdeloup, le Plan Landowski marque un tournant dans l'histoire du concert symphonique en France. L'État intègre désormais cette activité dans une politique culturelle globale privilégiant la constitution de pôles d'excellence mieux subventionnés. Cette transformation s'inscrit dans un processus inauguré en 1966 avec la fondation de la Direction de la musique au sein du jeune ministère des Affaires culturelles. La clarification de l'engagement de l'État fait suite à un siècle pendant lequel sa politique musicale n'avait jamais fait l'objet d'une définition claire et d'un investissement réel. Pour autant, l'État n'est pas totalement absent d'une activité symphonique que son soutien brouillon et timoré a pour le moins le mérite d'en éclairer la densité. Partout en France, des orchestres diffusent le répertoire symphonique dont il devient désormais nécessaire d'apprécier la qualité, la diversité et le renouvellement. Ce foisonnement se fait non pas contre ou avec l'État, mais malgré la faiblesse de son investissement. Pendant un siècle, des orchestres vivent et meurent avec pour seule aide de l'État sa caution sous la forme d'une subvention plus ou moins élevée, leur pérennité reposant avant tout sur leurs fonds propres, les recettes de billetterie et les aides des collectivités locales. On aurait néanmoins tort de ne pas observer attentivement l'engagement même insuffisant de l'État pendant un siècle. Il esquisse le tableau de la France symphonique, révèle son intensité, établit un classement dont l'un des enseignements est la suprématie d'un 
petit groupe de sociétés pendant une longue période. En elle-même, cette distinction est déjà le fruit de choix qui se dessinent progressivement et qui peuvent être assimilés à une politique musicale, même embryonnaire, à laquelle est associée une organisation dont la Commission des concerts est l'aboutissement. Mais celle-ci, plutôt que d'utiliser l'augmentation des moyens qui lui sont alloués pour encourager la diffusion de la musique sur l'ensemble du territoire en fait un instrument au service d'un projet corporatif et nationaliste que le Plan Landowski remet en cause.

\section{BIBLIOGRAPHIE}

ANSELMINI François, « Alfred Cortot et la création des Matinées nationales : l'Union sacrée mise en musique ", Revue de musicologie, t. 97, $\mathrm{n}^{\circ}$ 1, 2011, p. 61-84.

BÖDEKER Hans Erich et VEIT Patrice (dir.), Les sociétés de musique en Europe, 1700-1920. Structures, pratiques musicales, sociabilités, Berlin, Berliner-Wissenschafts-Verlag, 2007.

BÖDEKER Hans Erich, VEIT Patrice et WERNER Michael (dir.), Espaces et lieux de concert en Europe, 1700-1920, Berlin, Berliner-Wissenschafts-Verlag, 2008.

BÖDEKER Hans Erich, VEIT Patrice et WERNER Michael (dir.), Le concert et son public. Mutations de la vie musicale en Europe de 1780 à 1914 (France, Allemagne, Angleterre), Paris, Éditions de la Maison des sciences de l'homme, 2002.

BÖDEKER Hans Erich, VEIT Patrice et WERNER Michael (dir.), Organisateurs et formes d'organisation du concert en Europe, 1700-1920, Berlin, Berliner-Wissenschafts-Verlag, 2008.

CHIMÈNES Myriam (dir.), La vie musicale sous Vichy, Bruxelles, Complexe, 2001.

CHIMÈNES Myriam, « Le budget de la musique sous la IIIe République », DUFOURT Hugues et FAUQUET Joël-Marie (dir.), La musique du théorique au politique, Paris, Aux amateurs de livres, 1990, p. 261-312.

COINTET Michèle et Jean-Paul (dir.), Dictionnaire historique de la France sous l'Occupation, Paris, Tallandier, 2000.

DEYON Pierre, Paris et ses provinces. Le défi de la décentralisation, 1770-1992, Paris, Armand Colin, 1992. DRAG Christophe, La naissance de l'orchestre symphonique de Nancy et la création des Concerts populaires (1884-1914). Étude structurelle, musicale et financière, mémoire de maîtrise, université de Nancy II, 1993.

DUBOIS Vincent, La politique culturelle. Genèse d'une catégorie d'intervention publique, $1^{\text {re }}$ éd. 1999, éd. revue et corrigée, Paris, Belin, 2012.

GENET-DELACRoIX Marie-Claude, Art et État sous la IIIe République : le système des Beaux-arts, 1870-1940, Paris, Presses universitaires de la Sorbonne, 1992.

GOUBAULT Christian, La vie musicale à Rouen de 1830 à 1914, thèse de doctorat, Université de Paris IV, 1977. 
JARDIN Étienne, Le conservatoire et la ville. Les écoles de musique de Besançon, Caen, Rennes, Roubaix et Saint-Étienne au XIX ${ }^{e}$ siècle, thèse de doctorat, École des hautes études en sciences sociales, 2006. LE BAIL Karine, Musique, pouvoir, responsabilité : la politique musicale de la Radiodiffusion française, 1939-1953, thèse de doctorat, Institut d'études politiques, 2005.

MORABITO Fulvia (dir.), «En pèlerinage avec Liszt »: Virtuosos, Repertoire and Performing Venues in 19thCentury Europe, Turnhout, Brepols, 2014.

ROWDEN Clair, « Decentralisation and Regeneration at the Théâtre des Arts, Rouen, 1889-1891 », Revue de musicologie, t. 94, $\mathrm{n}^{\circ}$ 1, 2008, p. 139-180.

SAEZ Guy (dir.), La musique au cœur de l'État. Regard sur l'action publique de Marcel Landowski, préface de Maryvonne DE SAINT PULGENT, Paris, Collection du Comité d'histoire du ministère de la Culture et de la Communication, 2015.

SIMON Yannick, « Le concert en France des origines à 1 914. Orientations bibliographiques » [en ligne], avec la collaboration de Joann ÉLART, Étienne JARDIN et Patrick TAÏEB, $1^{\text {re }}$ éd. 2011, Publications numériques du CÉRÉdI, mise à jour en 2015.

SIMON Yannick, « Les voyages de Monsieur Pasdeloup. Propagation d'un modèle et d'un répertoire symphonique ", Ad Parnassum, vol. 15, n 30, october 2017, p. 95-134.

SIMON Yannick, Composer sous Vichy, Lyon, Symétrie, 2009.

SIMON Yannick, Jules Pasdeloup et les origines du concert populaire, Lyon, Symétrie, 2011.

SIMON Yannick, L'Association artistique d'Angers (1877-1893). Histoire d'une société de concerts populaires suivie du répertoire des programmes des concerts, Paris, Société française de musicologie, 2006.

SPRout Leslie A., Music for a « New Era » : composers and national identity in France, 1936-1946, Berkeley, University of California, 2000.

THIESSE Anne-Marie, «L'invention du régionalisme à la Belle Époque », Le Mouvement social, vol. 160, juillet-septembre 1992, p. 11-32.

VAISSE Pierre, La Troisième République et les peintres : recherches sur les rapports des pouvoirs publics et de la peinture en France de 1870 à 1914, thèse d'État, université de Paris IV, 1980.

\section{NOTES}

1. «En ce qui concerne la musique, là Messieurs vous avez les uns et les autres parfaitement raison. Il y a une part de carence de l'État, mais il y a aussi - il faut bien que vous le disiez - quelque chose d'assez étrange : c'est qu'on ne m'a pas attendu pour ne rien faire.» (discours d'André Malraux prononcé à l'Assemblée nationale le 14 octobre 1965). Voir "André Malraux» [en ligne], Assemblée nationale, http:// www.assemblee-nationale.fr (consulté le 30 octobre 2017).

2. COMMISSION NATIONALE POUR L'ÉTUDE DES PROBLÈMES DE LA MUSIQUE, Rapport général 1963-1964, Paris, Ministère d'État des Affaires culturelles, 1965, p. 49.

3. CHIMÈnES Myriam, « Le budget de la musique sous la III ${ }^{e}$ République », DUFOURT Hugues et FAUQUET Joël-Marie (dir.), La musique du théorique au politique, Paris, Aux amateurs de livres, 1990, p. 261-312. 
4. «Plan de dix ans pour l'organisation des structures musicales françaises », repris dans SAEZ Guy (dir.), La musique au cœur de l'État. Regard sur l'action publique de Marcel Landowski, préface de Maryvonne DE SAINT PULGENT, Paris, Collection du Comité d'histoire du ministère de la Culture et de la Communication, 2015, p. 177-181.

5. Son modèle pourrait être le Conseil supérieur des Beaux-arts. Voir GENET-DELACROIX Marie-Claude, Art et État sous la III République : le système des Beaux-arts, 1870-1940, Paris, Presses universitaires de la Sorbonne, 1992.

6. SIMON Yannick, Jules Pasdeloup et les origines du concert populaire, Lyon, Symétrie, 2011.

7. Sur l'histoire de la politique culturelle en France, voir DuBors Vincent, La politique culturelle. Genèse d'une catégorie d'intervention publique, $1^{\text {re }}$ éd. 1999, éd. revue et corrigée, Paris, Belin, 2012.

8. Voir l'« enquête sur la séparation des Beaux-arts et de l'État " publiée en 1904 par la revue Les Arts de la vie et évoquée par Vincent Dubois dans La politique culturelle (p. 36-37).

9. scudo Paul, «La musique en Province », Revue des deux mondes, 15 septembre 1857, p. $442-450$.

10. BRENET Michel, Les concerts en France sous l'Ancien Régime, Paris, Fischbacher, 1900.

11. sCUDo, « La musique en Province », p. 445.

12. Ibid, p. 447.

13. Sur Antoine-Louis Malliot, voir GoUBAULT Christian, La vie musicale à Rouen de 1830 à 1914, thèse de doctorat, Université de Paris IV, 1977, p. 465-470.

14. MALLIOT Antoine-Louis, La musique au théâtre, Paris, Amyot, 1863, p. 311-352.

15. Décret du 6 janvier 1864 relatif à la liberté de construire et d'exploiter un théâtre, Le Moniteur universel (Journal officiel de l'Empire français), 7 janvier 1864, p. 1.

16. MALLIOT Antoine-Louis, Pétition au Sénat. Fondation des théâtres impériaux de province, Rouen, Imprimerie Lapierre, 1865.

17. MALLIOT Antoine-Louis, Deuxième pétition au Sénat. Fondation des théâtres impériaux et des conservatoires de province, Paris, Amyot, 1866.

18. C'est dans cette double perspective que sera envisagée en 1890 la fondation d'une nouvelle institution de théâtre largement financée par l'État, mais qui aurait été installée à Rouen. Voir ROWDEN Clair, "Decentralisation and Regeneration at the Théâtre des Arts, Rouen, 1889-1891 ", Revue de musicologie, t. 94, n 1 (2008), p. 139-180.

19. Voir notamment AURIOL Henri, Décentralisation musicale, préface de Gabriel FAURÉ, Paris, E. Figuière, 1912 ; COUYBA Charles-Maurice, Les Beaux-arts et la nation, introduction de Paul-Louis GARNIER, Paris, Hachette, 1908 ; DEYON Pierre, Paris et ses provinces. Le défi de la décentralisation, 1770-1992, Paris, Armand Colin, 1992; THIESSE Anne-Marie, «L'invention du régionalisme à la Belle Époque ", Le Mouvement social, vol. 160, juilletseptembre 1992, p. 11-32.

20. SIMON Yannick, «Les voyages de Monsieur Pasdeloup. Propagation d'un modèle et d'un répertoire symphonique ", Ad Parnassum, vol. 15, nº 30, october 2017, p. 95-134; SIMON, Jules Pasdeloup et les origines du concert populaire. Le répertoire des quarantequatre programmes de concert a fait l'objet d'un dossier sur le site Dezède. SIMON Yannick, "Les voyages de Monsieur Pasdeloup (1864-1883)», Dezède [en ligne]. dezede.org/dossiers/id/46/ (consulté le 8 juin 2017). 
21. MORABito Fulvia (dir.), «En pèlerinage avec Liszt »: Virtuosos, Repertoire and Performing Venues in 19th-Century Europe, Turnhout, Brepols, 2014.

22. C'est notamment le cas à Lille en 1905. Voir notamment la lettre d'Émile Ratez [directeur du conservatoire et des concerts populaires de Lille] à « Monsieur et cher député ", 12 novembre 1905, Archives nationales de France [AnF], F/21/4626 (24)

23. Les conseils généraux ont été remplacés par les conseils départementaux en 2015.

24. SIMON Yannick, "Le concert en France des origines à 1914. Orientations bibliographiques » [en ligne], avec la collaboration de Joann ÉLART, Étienne JARDIN et Patrick TAÏEB, $1^{\text {re }}$ éd. 2011, Publications numériques du CÉRÉdI, mise à jour en 2015.

25. Voir plus spécifiquement BöDEKER Hans Erich, VEIT Patrice et WERNER Michael (dir.), Le concert et son public. Mutations de la vie musicale en Europe de 1780 à 1914 (France, Allemagne, Angleterre), Paris, Éditions de la Maison des sciences de l'homme, 2002; BÖDEKER Hans Erich, VEIT Patrice et WERNER Michael (dir.), Espaces et lieux de concert en Europe, 1700-1920, Berlin, Berliner-Wissenschafts-Verlag, 2008 ; BÖDEKER Hans Erich, VEIT Patrice et WERNER Michael (dir.), Organisateurs et formes d'organisation du concert en Europe, 1700-1920, Berlin, Berliner-Wissenschafts-Verlag, 2008; BÖDEKER Hans Erich et VEIT Patrice (dir.), Les sociétés de musique en Europe, 1700-1920. Structures, pratiques musicales, sociabilités, Berlin, Berliner-Wissenschafts-Verlag, 2007.

26. CHIMÈNES, « Le budget de la musique sous la III ${ }^{e}$ République ».

27. La Société des concerts du Conservatoire est effectivement financée par l'institution qui l'abrite et qui voit son budget entièrement pris en charge par l'État.

28. PASDELoup Jules, «Lettre du 23 janvier 1878 à "Messieurs les députés" », Le Ménestrel, 10 février 1878, p. 85. Cette pétition est reproduite dans SIMON, Jules Pasdeloup et les origines du concert populaire, p. 70-71.

29. SPRout Leslie A., Music for a "New Era»: composers and national identity in France, 1936-1946, Berkeley, University of California, 2000.

30. Les concerts Pasdeloup s'interrompent en 1887 après le décès de leur fondateur. Une société utilisant son nom voit le jour pendant la Première Guerre mondiale mais ne sera financée par l'État qu'à partir de 1927. Sur les Concerts Lamoureux voir SIMON Yannick, Charles Lamoureux, chef d'orchestre et directeur musical au XIXe siècle, Arles, Actes Sud/Palazzetto Bru Zane (à paraître).

31. Voir sIMON Yannick, L'Association artistique d'Angers (1877-1893). Histoire d'une société de concerts populaires suivie du répertoire des programmes des concerts, Paris, Société française de musicologie, 2006, p. 79-83.

32. CHAMBRE DES DÉPUTÉs, «Discussion sur le budget de l'exercice 1879 », ministère de l'Instruction publique, des Cultes et des Beaux-arts, partie relative au service des Beaux-arts, Journal officiel, 29 novembre 1878, p. 11175-11194.

33. SÉNAT, « Compte rendu de la séance du 3 décembre 1880 relative au vote du budget des dépenses de l'exercice 1881 , chapitre 51 du budget du ministère de l'instruction publique ", Journal officiel, 4 décembre 1880, p. 11882-11884.

34. Une confusion règne sur la place de Lyon dans cet ensemble. Voir SIMON, L'Association artistique d'Angers, p. 82.

35. Un amendement allant dans le même sens avait été repoussé l'année précédente. Voir CHAMBRE DES DÉPUTÉS, « Discussion sur le budget de l'exercice 1880 », ministère de 
l'Instruction publique, des Cultes et des Beaux-arts, partie relative au service des Beaux-arts, Journal officiel, 30 juillet 1879, p. 7753.

36. CHAMBRE DES DÉPUTÉS. «Rapport fait au nom de la commission du budget chargée d'examiner le projet de loi portant fixation du budget général des dépenses et des recettes de l'exercice 1881 (Ministère de l'instruction publique et des Beaux-arts, $2^{\mathrm{e}}$ section, Beaux-arts) », par M. Édouard Lockroy, député, annexe ${ }^{\circ} 2752$, séance du 17 juin 1880, Journal officiel, 21 juillet 1880, p. 8470-8471.

37. Pour la période antérieure à 1914, cette étude repose sur le dépouillement des cartons F/21/3985, 4007-4016, 4417-4418, 4545, 4548-4550, 4552, 4582. En ce qui concerne le Journal officiel, on trouvera, pour la période de la III ${ }^{e}$ République, une liste de rapports parlementaires sur le budget des Beaux-arts dans VAISSE Pierre, La Troisième République et les peintres: recherches sur les rapports des pouvoirs publics et de la peinture en France de 1870 à 1914, thèse d'État, université de Paris IV, 1980, p. 785-787.

38. On rappellera que Pasdeloup décède en 1887.

39. «Réponses aux notes de la Commission des comptes définitifs. Exercice 1907. Chapitre 19. Demande. Note 70, 23 mai 1911 », AnF, F21/4545 (2)

40. AnF, F/21/3985 (5)

41. CHIMÈNES, « Le budget de la musique sous la III ${ }^{e}$ République », p. 290-291.

42. AnF, F/21/4582. Quelques départements, notamment le Maine-et-Loire où évoluent les Concerts populaires d'Angers, ne figurent pas dans ce recensement pour des raisons indéterminées.

43. Dans un brouillon de lettre qu'elle doit adresser à la Commission des comptes définitifs en mai 1911, l'administration des Beaux-arts écrit que «les crédits inscrits à l'article 3 s'appliquant sans destination aux concerts populaires et aux sociétés musicales, l'administration des Beaux-arts n'a pas établi de répartition entre ces deux catégories de parties prenantes. » Voir «Réponses aux notes de la Commission des comptes définitifs / Exercice 1907 / Chapitre 19 / Demande - Note 70, 23 mai 1911 ", AnF, F/21/4545 (2)

44. Voir SIMON, L'Association artistique d'Angers (1877-1893), p. 82.

45. Sur ce point, Christophe Drag se montre très imprécis tout en confirmant que la subvention de l'État n'est pas reconduite systématiquement d'année en année. Voir DRAG Christophe, La naissance de l'orchestre symphonique de Nancy et la création des Concerts populaires (1884-1914). Étude structurelle, musicale et financière, mémoire de maîtrise, université de Nancy II, 1993, p. 89-96.

46. CHAMBRE DES DÉPUTÉS, "Séance du 1er décembre 1900 », Journal officiel (débats parlementaires), 11 décembre 1900, p. 2571.

47. Le nom des nouvelles villes est associé à un astérisque dans la première colonne de ce tableau qui ne prend en compte, naturellement, que les chiffres recensés dans les archives consultées. Seules des études ville par ville pourraient permettre de compléter ces données. L'isolement des sociétés de concerts symphoniques dans un ensemble qui inclut des sociétés musicales a été réalisé sur la base de plusieurs critères : titre de la société, pérennité de la société, ampleur de la subvention, taille de la ville. C'est, par exemple, en fonction de ces choix que l'Union symphonique de Périgueux, ayant reçu une subvention de 50 francs la seule année 1904, n'a pas été intégrée dans cette liste.

48. Cette appellation désigne peut-être la Société philharmonique fondée en 1815. 
49. « Notes sur les Concerts populaires des départements, s. d. [1911 ?], 4 p., AnF, F/ $21 / 3985(5)$

50. Ce recensement diffère de notre propre répertoire dans la mesure où il distingue les "concerts populaires» sans, du reste, préciser la définition retenue de cette expression.

51. JARDIN Étienne, Le conservatoire et la ville. Les écoles de musique de Besançon, Caen, Rennes, Roubaix et Saint-Étienne au XIXe siècle, thèse de doctorat, École des hautes études en sciences sociales, 2006.

52. Lettre de Julien Koszul au directeur des Beaux-arts, 13 novembre 1895, AnF, F/ 21/4627 (19)

53. AnF, F/21/4627 (19)

54. AnF, F/21/4628 (4)

55. Armand Gouzien est nommé par un arrêté du 15 mars 1880, mentionné par luimême dans un document figurant dans son dossier de légion d'honneur mais qui ne semble pas avoir paru au Journal officiel. Voir AnF, LH/1183/5

56. Voir SIMON, L'Association artistique d'Angers, p. 52, 73-75, 81.

57. Sur le rôle des inspecteurs de l'enseignement musical, voir JARDIN, Le conservatoire et la ville.

58. Désiré-Alexandre Batton (1842-1855), Ambroise Thomas (1855-1871), Henri Reber (1871-1880) et Ernest Reyer (1881-1884).

59. Il s'agit de Gustave Canoby, Théodore Dubois, Ernest Guiraud, Victorin de Joncières, Henri Maréchal, Charles Lenepveu, Émile Paladilhe, Ernest Reyer et Charles Vervoitte. AnF, F/21/5345.

60. Un arrêté du 7 mai 1896 réduira le nombre des inspecteurs à cinq. AnF, F/21/5345

61. Pourtant mentionnés sur l'arrêté du 28 janvier 1884, Émile Paladilhe et Charles Vervoitte ne prennet pas leurs fonctions, le premier pour une raison inconnue et le second en raison de son décès le 16 avril 1884.

62. AnF, F/21/4627 (19)

63. AnF, F/21/4627 (19)

64. AnF, F/21/4627 (19)

65. La Revue musicale, $1^{\mathrm{er}}$ février 1904, p. 98.

66. AnF, F/21/4628 (4)

67. Pour la période comprise entre 1914 et 1929, cette étude repose sur le dépouillement des cartons $\mathrm{F} / 21 / 3985,4545,4549,4552$, 4582, 4626-4628.

68. AnF, F/21/4545 (19)

69. AnF, F/21/4545 (8). Sur la propagande artistique à l'étranger et le rôle déterminant joué dans ce domaine par le pianiste Alfred Cortot, voir ANSELMINI François, «Alfred Cortot et la création des Matinées nationales : l'Union sacrée mise en musique ", Revue de musicologie, t. 97, $\mathrm{n}^{\circ} 1$ 1, 2011, p. 61-84.

70. La confirmation du démembrement des sociétés de concerts suppose un travail de recherche que nous n'avons pas été en mesure de réaliser dans toutes les villes évoquées.

71. Villes nouvelles* et sociétés nouvelles**. 
72. « Notes sur le crédit des concerts », [1928], AnF, F/21/3985 (5)

73. AnF, F/21/4628 (4)

74. Ibid.

75. Voir « Les taxes sur les spectacles », 1er mai 1930, 7 p., AnF, F/21/4552 (2)

76. Voir GENET-DELACROIX, Art et État sous la III République.

77. Sous ses différentes formes et dénominations, celle à laquelle nous donnerons le titre générique de Commission des concerts apparaît dans de nombreux cartons du fonds $\mathrm{F} / 21$ : 4582, 4626, 5200, 5358-5359, 8441, 8445, 8643. Voir aussi le carton F/21/NC/ 472 (carton non classé en 2017) et, pour la période la plus récente, le carton 19860731.

78. Le caractère officiel de ce comité n'est pas avéré. Voir ROWDEN, «Decentralisation and Regeneration at the Théâtre des Arts, Rouen, 1889-1891 », p. 144-147.

79. La Revue musicale, 15 juillet 1905, p. 394.

80. Voir La Revue musicale, 15 mars 1906, p. 159 et $1^{\text {er }}$ avril 1906, p. 186.

81. Journal officiel, 25 mai 1912, p. 4740.

82. AnF, F/21/4582 (4)

83. Journal officiel, 17 novembre 1928, p. 12159-12160.

84. L'HôPITAL Charles, Commission pour la rénovation et le développement des études musicales (1928-1931), Rapport de M. Charles L'Hôpital, Paris, Comité national de propagande pour la musique, 1931.

85. La question du cahier des charges des sociétés de concerts institutionnalisées fera l'objet d'une étude spécifique.

86. « Procès-verbal », 22 janvier 1931, AnF, F/21/4626

87. Le groupe de travail réunit Alfred Bachelet (chef de l'orchestre des Concerts du conservatoire de Nancy), Albert Wolff (Concerts Lamoureux), Gabriel Pierné (Concerts Colonne), Philippe Gaubert (Société des concerts du Conservatoire), René Gadave (chef du bureau des Théâtres), Henri Rabaud (directeur du Conservatoire) et Alfred Bruneau (inspecteur général de l'enseignement musical).

88. AnF, F/21/4626

89. La demande doit comprendre : $a /$ les statuts (à la première demande) ; b/ un état indiquant le nom du chef, le nombre des instrumentistes et des choristes, la répartition par pupitre, les membres étrangers, la salle, le nombre de places et les catégories tarifaires, les coordonnées de celui auquel doit être adressée la subvention; c/ le programme des concerts donnés pendant la saison.

90. "Notre enquête. La grande pitié des Concerts en France", Le Courrier musical et théâtral, vol. XXXII, nº 16, $1^{\text {er }}$ octobre 1930, p. 533-550.

91. CHARPENTIER Raymond, «La grande pitié de la musique symphonique en France. La crise de la symphonie ", Le Courrier musical et théâtral, vol. XXXII, n 17, 15 octobre 1930, p. 589-596.

92. LALO Pierre, «La grande pitié de la musique symphonique en France », Le Courrier musical et théâtral, vol. XXXII, n 19, 15 novembre 1930, p. 661-662.

93. « Note sur les crédits à demander par l'Administration des Beaux-arts pour parer aux conséquences de la crise économique ", 15 décembre 1931, AnF, F/21/4626

94. Voir les procès verbaux des séances, AnF, F/21/4582 
95. AnF, F/21/4628

96. AnF, F/21/4628 (6-7)

97. Villes nouvelles* et sociétés nouvelles**.

98. Le Trigentuor instrumental lyonnais fusionne avec la Société des grands concerts en 1938 pour créer l'Association philharmonique de Lyon.

99. C'est précisément pendant cette période, en 1943, qu'Alfred Bruneau sera remplacé par Joseph Szyfer. Nommé inspecteur de l'enseignement musical en 1941, cet obscur compositeur et chef d'orchestre est né à Varsovie en 1887. Naturalisé français au lendemain de la Première Guerre mondiale à laquelle il a participé comme volontaire dans l'armée française, Szyfer dirige à neuf reprises sous l'Occupation l'orchestre de la Société des concerts populaires d'Angers. Il décède en 1947.

100. La situation d'André Bloch sous l'Occupation est singulière: inspecteur de l'enseignant musical et professeur au Conservatoire, il avait été contraint de faire valoir ses droits à la retraite le 1er mai 1940. Refusant cette perspective, il obtint du directeur général des Beaux-arts la possibilité de rester en fonction. Par deux arrêtés du 18 décembre 1940 s'appuyant sur l'article 7 de la loi du 3 octobre 1940 portant statut des juifs, il est mis fin à ses fonctions à compter du 19 décembre 1940. Dans le même temps, Bloch est nommé " professeur honoraire du Conservatoire " (un changement de statut qui s'applique pareillement au pianiste Lazare Lévy) et « inspecteur honoraire de l'enseignement musical ». AnF, F/21/ 5345. Voir aussi GRIBENSKI Jean, «L'exclusion des juifs du Conservatoire (1940-1942) », CHIMÈNES Myriam (dir.), La vie musicale sous Vichy, Bruxelles, Complexe, 2001, p. 145.

101. Il ne nous a pas été permis de consulter tous les procès verbaux des séances de la Commission des concerts tenues au cours des années ayant précédé le déclenchement de la guerre.

102. AnF, F/21/5200

103. Sour les comités d'organisation créés sous Vichy, voir SIMON Yannick, Composer sous Vichy, Lyon, Symétrie, 2009, p. 64-85.

104. Édouard Colonne étant d'origine juive, les autorités allemandes ont exigé que soit débaptisée la société qui porte son nom et que ce dernier soit remplacé par celui de son successeur à la tête de l'orchestre, Gabriel Pierné.

105. AnF, F/21/8441

106. Claude Delvincourt a été nommé à la tête du Conservatoire en remplacement d'Henri Rabaud par un arrêté du 22 février 1941 publié au Journal officiel du 31 mars 1941.

107. LAEDERICH Alexandra, «Les associations symphoniques parisiennes », CHIMÈNES (dir.), La vie musicale sous Vichy, p. 217-233.

108. AnF, F/21/8441

109. Journal officiel, 21 décembre 1941, p. 5482-5484.

110. Journal officiel, 18 avril 1942, p. 1487. L'année suivante, il prendra le titre de Comité professionnel de l'art musical et de l'enseignement libre de la musique.

111. Journal officiel, 30 novembre, 1941, p. 5173. 
112. « Note sur les initiatives prises par le secrétariat général des Beaux-arts en faveur de la musique, des concerts et de l'enseignement de la musique depuis le mois de juillet 1940 », s.d. [1942], AnF, F/21/NC/472

113. Pour une carte de la France sous l'Occupation, voir coINTET Michèle et Jean-Paul (dir.), Dictionnaire historique de la France sous l'Occupation, Paris, Tallandier, 2000, p. 716.

114. Villes nouvelles* et sociétés nouvelles**.

115. AnF, F/21/8442. Si l'acceptation des femmes dans les associations de concerts parisiennes semble postérieure à la formulation de cet avis, il est avéré que des musiciennes sont admises dans les phalanges en dehors de la capitale depuis plusieurs décennies.

116. AnF, F/21/8442

117. Sur les troubles à l'occasion de la rentrée parisienne de Cortot en janvier 1947, voir CHIMÈNES, "Alfred Cortot et la politique musicale du gouvernement de Vichy », La vie musicale sous Vichy, p. 49.

118. AnF, F/21/8442. Sur Marcelle Meyer, voir LE BAIL Karine, Musique, pouvoir, responsabilité: la politique musicale de la Radiodiffusion française, 1939-1953, thèse de doctorat, Institut d'études politiques, 2005, 4 vol., p. 625-626.

119. AnF, $\mathrm{F} / 21 / 8442$

120. AnF, $\mathrm{F} / 21 / \mathrm{NC} / 418$

121. AnF, 19860731/1

122. AnF, 19860731/1. Voir Commission nationale pour l'étude des problèmes de la musique. Rapport général 1963-1964, Paris, Ministère d'État des Affaires culturelles, $1965,133 \mathrm{p}$.

123. AnF, F/21/8445 (4)

124. AnF, F/21/8442

125. AnF, F/21/8442

126. AnF, $\mathrm{F} / 21 / 8443$

127. AnF, F/21/8442

128. À partir de cette période, l'établissement d'un tableau indiquant, non pas la liste des sociétés subventionnées mais le montant des subventions devient difficile à réaliser. La forte inflation qui caractérise cette période amène l'État à effectuer plusieurs versements au cours de l'année sans qu'il soit toujours possible de les identifier ni même d'en connaître le nombre. Par ailleurs, la création du ministère des Affaires culturelles en 1958 a entraîné une nouvelle politique de conservation des archives.

129. En francs courants : 1683000 francs en 1943 et 6310000 francs en 1958 ; en euros (2015) : 387090 euros et 126200 euros.

130. "Séance du 11 décembre 1947 ; Second semestre 1947, demandes de subvention rejetées ", AnF, F/21/8442

131. Commission des concerts symphoniques, séance du 29 novembre 1951, AnF, F/ $21 / 8443$

132. AnF, 19860731/1

133. AnF, $19860731 / 1$ 
134. AnF, $19860731 / 1$

135. AnF, 19860731/1

136. Ils passent de 6310000 anciens francs à 158500 nouveaux francs - 126200 euros

(2015) à 177520 euros, soit une augmentation de $40 \%$.

\section{INDEX}

Mots-clés : vie musicale, concerts, France, xixe siècle, xxe siècle, régions, subventionnement, politique musicale, décentralisation, goût musical

\section{AUTEUR}

\section{YANNICK SIMON}

Professeur à l'université de Rouen, Yannick Simon travaille sur la vie musicale en France sous la III République et sous l'Occupation. Il est l'auteur de La Sacem et les droits des auteurs et compositeurs juifs sous l'Occupation (La Documentation française, 2000) et de Composer sous Vichy (Symétrie, 2009). Il a dirigé, avec Myriam Chimènes, la publication de La musique à Paris sous l'Occupation (Fayard, 2013). Il effectue parallèlement des recherches sur la diffusion de la musique symphonique, de la musique de chambre et de l'opéra dans l'espace musical français. Il a consacré deux ouvrages aux concerts populaires : L'Association artistique d'Angers (Société française de musicologie, 2006) et Jules Pasdeloup et les origines du concert populaire (Symétrie, 2011). Il est aussi l'auteur de Lohengrin : un tour de France, 1887-1891 (Presses universitaires de Rennes, 2015). Il est l'un des trois fondateurs et administrateurs du site Dezède. 